\title{
Dynamic Optimization Design of Cranes Based on Human-Crane-Rail System Dynamics and Annoyance Rate
}

\author{
Yunsheng Xin, ${ }^{1}$ Gening $X u^{1}{ }^{1}$ and Nina $\mathrm{Su}^{2}$ \\ ${ }^{1}$ School of Mechanical Engineering, Taiyuan University of Science and Technology, Taiyuan 030024, China \\ ${ }^{2}$ College of Economics and Management, Taiyuan University of Technology, Taiyuan 030024, China \\ Correspondence should be addressed to Gening Xu; xugening@tyust.edu.cn
}

Received 22 November 2016; Revised 22 January 2017; Accepted 7 February 2017; Published 2 March 2017

Academic Editor: Salvatore Strano

Copyright (c) 2017 Yunsheng Xin et al. This is an open access article distributed under the Creative Commons Attribution License, which permits unrestricted use, distribution, and reproduction in any medium, provided the original work is properly cited.

\begin{abstract}
The operators of overhead traveling cranes experience discomfort as a result of the vibrations of crane structures. These vibrations are produced by defects in the rails on which the cranes move. To improve the comfort of operators, a nine-degree-of-freedom (nine-DOF) mathematical model of a "human-crane-rail" system was constructed. Based on the theoretical guidance provided in ISO 2631-1, an annoyance rate model was established, and quantization results were determined. A dynamic optimization design method for overhead traveling cranes is proposed. A particle swarm optimization (PSO) algorithm was used to optimize the crane structural design, with the structure parameters as the basic variables, the annoyance rate model as the objective function, and the acceleration amplitude and displacement amplitude of the crane as the constraint conditions. The proposed model and method were used to optimize the design of a double-girder $100 \mathrm{t}-28.5 \mathrm{~m}$ casting crane, and the optimal parameters are obtained. The results show that optimization decreases the human annoyance rate from $28.3 \%$ to $9.8 \%$ and the root mean square of the weighted acceleration of human vibration from $0.59 \mathrm{~m} / \mathrm{s}^{2}$ to $0.38 \mathrm{~m} / \mathrm{s}^{2}$. These results demonstrate the effectiveness and practical applicability of the models and method proposed in this paper.
\end{abstract}

\section{Introduction}

In 1975, Kelsey and Hardy [1] proposed that vibration of motor vehicles was related to human lumbar disease. Many researchers subsequently evaluated the effects of mechanical shock and vibration on human health. Xu et al. [2] investigated the relationship between low back pain (LBP) and occupational activities by means of logistic regression analysis of data on more than 5,000 people and obtained an odds ratio (OR) of 1.30 for whole-body vibration. Schwarze et al. [3] investigated 388 equipment operators exposed to vibrations and found that the human body can tolerate an $8 \mathrm{~h}$ energy-equivalent frequency-weighted amplitude limit of $0.6 \mathrm{~m} / \mathrm{s}^{2}$ per day. Beyond this limit, operators are prone to a medical diagnosis of "lumbar syndrome" (defined as "any kind of symptoms in the lumbar region and in the sacral area for which a vertebral cause could be assumed after differential diagnosis"). Bovenzi et al. [4] compared the risk of occupational disease among four types of professional equipment operators in a mechanical vibration environment.
For workers engaged in this work for long periods of time, the frequency of LBP was found to be $53 \%$, and the four occupations were found to have a higher lifetime probability of LBP (for crane operators, the lifetime probability was close to $80 \%$ ). In a subsequent study, Bovenzi [5] followed up with more than 200 equipment operators and found that the cumulative incidence of LBP due to mechanical vibration was $38.6 \%$. Of the operators surveyed, $16.8 \%$ suffered from highintensity pain, and $14.4 \%$ had been diagnosed with a severe disability.

Overhead cranes, which are important pieces of specialized equipment used in modern material handling, inevitably experience mechanical vibrations during their operation [6]. The weights of overhead cranes, the lack of suspension damping systems, rail defects, and other factors combine to ensure that crane operators are subjected to vibrations in the work environment. In researching complaints from overhead crane operators regarding lumbar disease, Grogan et al. [7] found that LBP caused losses in working time and efficiency in vibration environments at acceleration of $0.4 \mathrm{~m} / \mathrm{s}^{2}$ or more 
and was associated with other ailments. Bongers et al. [8] reviewed the social security data for 743 crane operators in an iron and steel company and found that crane operators had a much higher proportion of intervertebral disc disease than manual or maintenance workers. In a ten-year study of crane operators, Bongers et al. $[8,9]$ found that operators that had worked with cranes for more than 5 years were more likely to suffer from back diseases than operators in a control group. Exposure to vibration in the work environment, poor driving posture, and unpredictable weather conditions were identified as the main factors responsible. Other research has shown that the 12-month prevalence of LBP is in the range of $40-60 \%$ for crane operators and that the frequency of LBP is $27-34 \%[10,11]$. In a cross-sectional study of 78 crane operators conducted in Italy [12], the overall incidence of lumbar disease was $38.5 \%$, which was far greater than that for the rest of the population in the same age group. Despite differences in the study design, mode of work exposure assessment, choice of study and control groups, and characterization of health conditions, most previous studies on the subject have shown that crane operators are at risk of developing lumbar diseases.

There are many reasons for crane vibration, but the main reason is believed to be rail defects [13]. Seams created in crane rails during installation are susceptible to installation errors and subsidence of the rail foundation, both of which can often increase the impact force between the crane and the rail. Domazet et al. [14] found that, over the long term, such impacts exacerbate rail defects and greatly reduce the service lives of cranes. Raymond [15] analyzed the cause of failure of heavy gantry cranes that occurred in 1985 and found that rail defects were constantly subjected to vibratory shocks during reciprocating motion. Kulka et al. [16] identified a variety of factors, including vibrations, which cause damage to a crane's rail. According to Rettenmeier et al. [17], when a moving load is subjected to rail vibration, rail cracks are propagated in crane rails, which results in a vicious circle of increased vibration and cracking.

Although crane rail defects have been shown to play an important role in vibration, few studies on crane rail defects have been performed, and a complete system dynamics model for crane vibration is still lacking. In this study, we considered a human-crane-rail system, including rail defects, and constructed a nine-degree-of-freedom (nineDOF) mathematical model for the system. We used Newmark method to solve the vibration equation and calculate the root mean square of the weighted acceleration. The fitness function is composed of two parts. One part is a vibration evaluation model that is based on ISO 2631-1 [18] and the annoyance rate. The other part is the constraint condition. The value of the fitness function is obtained by adding the root mean square of the weighted acceleration. After several iterations, the optimal values of the parameters are obtained. The optimal parameter values are then input into the vibration equation to obtain the optimized acceleration response in the time domain, and the power spectral density function is used to verify the effectiveness of the optimization process.

\section{Review of Literature}

The occupational diseases caused by human vibrations are described in detail in the Introduction. In this section, we discuss issues associated with the main methods and technical means used in this study. In this paper, by constructing a "human-crane-rail" system model, we put forward an evaluation method based on ISO2631-1 combining with the annoyance rate, to optimize the crane structure parameters. Based on this sequence, literature is divided into three categories as follows: (1) crane vibration models, (2) comfort evaluation methods, and (3) optimization methods.

(1) Crane Vibration Models. Many researchers have performed in-depth studies of crane vibration. Oguamanam et al. [19] established an Euler-Bernoulli equation to study the vibration response of a fixed crane girder. Previous studies have focused on the swinging of sling loads during the crane conveying process, using a simplified model for double pendulum vibration and a system for elimination of vibration through feedback control measures [20-23]. Using the finite element method, $\mathrm{Wu}$ [24] and Zrnić et al. [25] constructed multi-degree-of-freedom vibration models for crane structures to analyze the effects of the length of wire rope, the damping ratio, and the tilt angle of the sling load on the structural vibration. Other studies on crane vibration have focused mainly on the structural fatigue $[13,26-28]$ and dynamic properties $[29,30]$ of cranes.

(2) Comfort Evaluation Methods. ISO 2631-1 [31] is an internationally accepted standard for evaluating human vibration comfort. Paddan and Griffin [32] evaluated the vibration comfort of 100 vehicles (covering 14 categories) according to the British Standard BS 6841 (1987) and ISO 2631-1 (1997). The results showed that ISO 2631-1 allowed longer daily exposure to body vibration than BS 6841. Paddan and Griffin [33] also proposed a method for adjusting the seat vibration isolation to improve operator comfort. Langer et al. [34] conducted an evaluation of agricultural tractor vibration comfort and found that the ISO 2631-1 vibration exposure value was approximately $0.5 \mathrm{~m} / \mathrm{s}^{2}$. Based on the results, Langer et al. made recommendations to improve the vibration comfort of agricultural tractors. Zhou and Chen [35] used ISO 2631-1 to evaluate the vibration of various vehicles passing over a longspan bridge. The results showed that the overall vibration values of light cars and heavy truck were less than $0.315 \mathrm{~m} / \mathrm{s}^{2}$, which is a threshold level for ride discomfort. Yang et al. [36] conducted research on the annoyance rate using software for dynamic analysis and simulation of trucks and proposed a method for optimizing ride comfort by establishing a quantitative relationship between subjective assessments and objective evaluation of comfort.

(3) Optimization Methods. Tung et al. [37] optimize vehicle suspension system by using PSO algorithm, to guarantee all the states of vehicles in an optimal exponential decay in nearly real-time, and ride comfort is significantly improved. Zhang et al. [38] use the PSO algorithm in optimization of the crack parameters. The particle swarm optimization (PSO) 
method was selected for use in this study. The essence of PSO is that three types of information (current position, global extreme values, and individual extreme values) are used to select the next iteration position of the particle. Compared with other algorithms, PSO approximates optimal solutions rapidly, and it can optimize the parameter values of a system effectively [39]. PSO offers obvious advantages in solving optimization problems for continuous functions [40], including its ease of implementation and its robustness. PSO has been used successfully to solve multidimensional optimization problems in artificial neural network [41] and support vector machine [42] research. In this study, PSO was used to optimize the parameters of crane structures.

Some previous studies on crane vibration and operator discomfort have suffered from limitations, such as the following: (1) use of a crane structure vibration model involving only the mechanical structure, without consideration of the full human-machine-environment system; (2) evaluation of human vibration comfort based only on anthropometry and ISO 2631-1, without the use of theoretical model for human comfort analysis; and (3) the reliance of ISO 2631-1 on a threshold vibration value as a criterion for assessing the degree of comfort, which provides insufficient continuity and quantification in evaluating human body vibration comfort.

This paper presents an annoyance rate model for use in evaluating vibration comfort. A nine-DOF mathematical model of the human-crane-rail system was developed for use in optimization of the crane's structural parameter values. This paper presents a dynamic design optimization method for cranes based on human-crane-rail system dynamics and the annoyance rate. Taking the crane structure parameters as basic variables, the operator's annoyance rate model as the objective function, and the combination of the acceleration amplitude and the displacement amplitude as the constraint condition, the PSO algorithm is used to obtain optimized values of the crane's structural design parameter to minimize crane vibration, improve vibration comfort, and thus reduce the likelihood of related occupational diseases.

\section{Crane Vibration System Modeling}

When a crane operates on rails while loading and unloading cargo, bending of the rails and horizontal gaps and vertical discontinuities (steps) at the rail joints produce vertical dynamic impact effects, the magnitudes of which depend on the crane's structure (the mass distribution, elasticity of the crane, and the support pattern), the running speed, the wheel diameter, and the condition of the rail joints. These factors should therefore be considered in constructing a vibration model of a human-crane-rail system.

The main causes of vibration of a crane structure are displacement of the rail and joint defects. During starting or braking of the cart, the main girder and end girder of the crane experience little elastic deformation in $Z$ direction (see Figure 1). However, when the cart is moving at a uniform speed, the main girder is free from inertial force, and the deformation in $Z$ direction disappears quickly under the action of structural damping. The vibration of the crane structure in $Z$ direction is negligible. At the same time, the

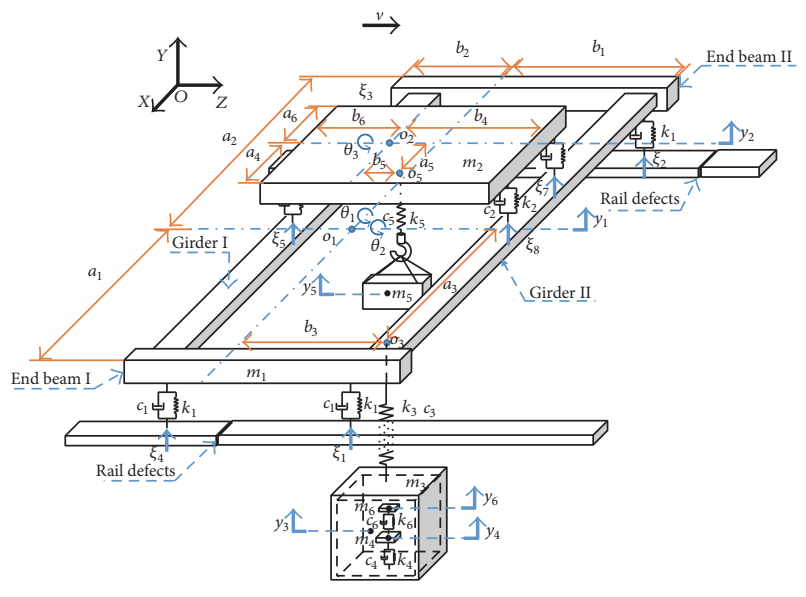

FIgURE 1: Human-crane-rail system vibration model.

gap between the crane wheel and the rail makes the main girder in $X$ direction (see Figure 1) produce minimal elastic deformation. This elastic deformation is invisible during operation, so the vibration in $X$ direction is negligible. In addition, because of the great size of the crane, the lack of a suspension system, and the short impact time of rail defects, the crane operating speed is not affected by rail impacts, and the amplitude of each component is very small. Thus, in studying the impacts of rail defects on crane operators, the system can be simplified to a linear system. To simplify the calculations, the following hypotheses are made:

(1) The vibration of the crane structure in the horizontal direction and the transformation of the main girder and end girder in $X$ and $Z$ directions are excluded.

(2) Each component is simplified into a mass block that vibrates slightly about its equilibrium position.

(3) The rigidity and damping of the system are linearly related to the relevant displacement and speed.

(4) The horizontal velocity at which the crane passes over a rail defect remains constant.

(5) The rail exciting forces of the operating wheels are identical.

(6) The girder rail has no defects, except for steps at joints and gap defects.

The natural frequency range of organs of the human body is 3 to $17 \mathrm{~Hz}$, the natural frequency of the human head is 8 to $12 \mathrm{~Hz}$, the natural frequency of the abdominal viscera is 4 to $6 \mathrm{~Hz}$, and the resonance frequency of the human body as a whole is approximately $7.5 \mathrm{~Hz}$. When an external excitation frequency is close to the natural frequency of the human body, the body will resonate, which makes people feel quite uncomfortable and can even endanger human life. In this study, we evaluated the impact of vertical vibration on the human body as a whole from the perspective of comfort, which is consistent with the criteria defined in ISO 2631-1 for the evaluation of the comfort of the operators of mechanical equipment. Thus, the human body as a whole is discussed in the model simplification. 
3.1. Mathematical Model of Crane. Figure 1 shows the physical model of the crane vibration system developed on the basis of the stated hypotheses. This can be regarded as a constantcoefficient linear dynamic system. The meanings and initial values of the parameters in the vibration system are provided in Appendix A. The following motions are considered: (1) the vibration of the crane cart in $Y$ direction and its rotation around $x$-and $z$-axes; (2) the trolley's movement in the $Y$ direction and its rotation around the $z$-axis; and (3) the payload, cab, seat, and human vibrations in $Y$ direction.

In Figure 1, the generalized coordinates $y_{i}$ and $\theta_{k}$ are based on separate equilibrium positions. The systematic kinetic energy can be expressed as

$$
T=\sum_{1}^{6} \frac{1}{2} m_{i} \dot{y}_{i}^{2}+\sum_{1}^{3} \frac{1}{2} J_{k} \dot{\theta}_{k}^{2}
$$

The systematic potential energy $U$ is

$$
\begin{aligned}
U= & \frac{1}{2} k_{1}\left[\left(\xi_{1}(t)+a_{1} \theta_{2}-b_{1} \theta_{1}-y_{1}\right)^{2}\right. \\
& +\left(\xi_{2}(t)-b_{1} \theta_{1}-a_{2} \theta_{2}-y_{1}\right)^{2} \\
& +\left(\xi_{3}(t)+b_{2} \theta_{1}-y_{1}-a_{2} \theta_{2}\right)^{2} \\
& \left.+\left(\xi_{4}(t)+a_{1} \theta_{2}+b_{2} \theta_{1}-y_{1}\right)^{2}\right]+\frac{1}{2} \\
& \cdot k_{2}\left[\left(\xi_{5}(t)+a_{4} \theta_{3}-y_{2}\right)^{2}+\left(\xi_{6}(t)-a_{6} \theta_{3}-y_{2}\right)^{2}\right. \\
& \left.+\left(\xi_{7}(t)-a_{6} \theta_{3}-y_{2}\right)^{2}+\left(\xi_{8}(t)+a_{4} \theta_{3}-y_{2}\right)^{2}\right]+\frac{1}{2} \\
& \cdot k_{3}\left(y_{3}+a_{3} \theta_{2}-b_{3} \theta_{1}-y_{1}\right)^{2}+\frac{1}{2} k_{4}\left(y_{4}-y_{3}\right)^{2}+\frac{1}{2} \\
& \cdot k_{5}\left(y_{5}+a_{5} \theta_{3}-y_{2}\right)^{2}+\frac{1}{2} k_{6}\left(y_{6}-y_{4}\right)^{2} .
\end{aligned}
$$

The systematic dissipated energy $D$ is

$$
\begin{aligned}
D & =\frac{1}{2} c_{1}\left[\left(\dot{\xi}_{1}(t)+a_{1} \dot{\theta}_{2}-b_{1} \dot{\theta}_{1}-\dot{y}_{1}\right)^{2}\right. \\
& +\left(\dot{\xi}_{2}(t)-b_{1} \dot{\theta}_{1}-a_{2} \dot{\theta}_{2}-\dot{y}_{1}\right)^{2} \\
& +\left(\dot{\xi}_{3}(t)+b_{2} \dot{\theta}_{1}-\dot{y}_{1}-a_{2} \dot{\theta}_{2}\right)^{2} \\
& \left.+\left(\dot{\xi}_{4}(t)+a_{1} \dot{\theta}_{2}+b_{2} \dot{\theta}_{1}-\dot{y}_{1}\right)^{2}\right]+\frac{1}{2} \\
& \cdot c_{2}\left[\left(\dot{\xi}_{5}(t)+a_{4} \dot{\theta}_{3}-\dot{y}_{2}\right)^{2}+\left(\dot{\xi}_{6}(t)-a_{6} \dot{\theta}_{3}-\dot{y}_{2}\right)^{2}\right. \\
& \left.+\left(\dot{\xi}_{7}(t)-a_{6} \dot{\theta}_{3}-\dot{y}_{2}\right)^{2}+\left(\dot{\xi}_{8}(t)+a_{4} \dot{\theta}_{3}-\dot{y}_{2}\right)^{2}\right]+\frac{1}{2} \\
& \cdot c_{3}\left(\dot{y}_{3}+a_{3} \dot{\theta}_{2}-b_{3} \dot{\theta}_{1}-\dot{y}_{1}\right)^{2}+\frac{1}{2} c_{4}\left(\dot{y}_{4}-\dot{y}_{3}\right)^{2}+\frac{1}{2} \\
& \cdot c_{5}\left(\dot{y}_{5}+a_{5} \dot{\theta}_{3}-\dot{y}_{2}\right)^{2}+\frac{1}{2} c_{6}\left(\dot{y}_{6}-\dot{y}_{4}\right)^{2} .
\end{aligned}
$$

The Lagrange equation of the nonconservative system is

$$
\frac{d}{d_{t}}\left(\frac{\partial T}{\partial \dot{y}_{i}}\right)-\frac{\partial T}{\partial y_{i}}+\frac{\partial U}{\partial y_{i}}+\frac{\partial D}{\partial \dot{y}_{i}}=Q_{i} \quad(i=1,2, \ldots, n) .
$$

In this equation, $T$ is the systematic kinetic energy, $U$ the systematic potential energy, $D$ is the systematic energy dissipation function; $\partial D / \partial \dot{y}_{i}$ is the damping force generated by the energy dissipation function $D, Q_{i}$ is the generalized exciting force acting on the exterior, $y_{i}$ is a generalized coordinate, and $\dot{y}_{i}$ is a generalized velocity.

The system's differential equation of motion can be deduced from (4):

$$
\begin{aligned}
& m_{1} \ddot{y}_{1}+k_{1}\left[4 y_{1}-2 a_{1} \theta_{2}+2 a_{2} \theta_{2}-2 b_{2} \theta_{1}+2 b_{1} \theta_{1}\right. \\
& \left.-\xi_{1}(t)-\xi_{2}(t)-\xi_{3}(t)-\xi_{4}(t)\right]+c_{1}\left[4 \dot{y}_{1}-2 a_{1} \dot{\theta}_{2}\right. \\
& +2 a_{2} \dot{\theta}_{2}-2 b_{2} \dot{\theta}_{1}+2 b_{1} \dot{\theta}_{1}-\dot{\xi}_{1}(t)-\dot{\xi}_{2}(t)-\dot{\xi}_{3}(t) \\
& \left.-\dot{\xi}_{4}(t)\right]+k_{3}\left(y_{1}+b_{3} \theta_{1}-a_{3} \theta_{2}-y_{3}\right)+c_{3}\left(\dot{y}_{1}\right. \\
& \left.+b_{3} \dot{\theta}_{1}-a_{3} \dot{\theta}_{2}-\dot{y}_{3}\right)=0 \\
& m_{2} \ddot{y}_{2}+k_{2}\left[4 y_{2}-2 a_{4} \theta_{3}+2 a_{6} \theta_{3}-\xi_{5}(t)-\xi_{6}(t)\right. \\
& \left.-\xi_{7}(t)-\xi_{8}(t)\right]+c_{2}\left[4 \dot{y}_{2}-2 a_{4} \dot{\theta}_{3}+2 a_{6} \dot{\theta}_{3}-\dot{\xi}_{5}(t)\right. \\
& \left.-\dot{\xi}_{6}(t)-\dot{\xi}_{7}(t)-\dot{\xi}_{8}(t)\right]+k_{5}\left(y_{2}-a_{5} \theta_{3}-y_{5}\right) \\
& +c_{5}\left(\dot{y}_{2}-a_{5} \dot{\theta}_{3}-\dot{y}_{5}\right)=0 \text {, } \\
& m_{3} \ddot{y}_{3}+k_{3}\left(y_{3}+a_{3} \theta_{2}-b_{3} \theta_{1}-y_{1}\right)+c_{3}\left(\dot{y}_{3}+a_{3} \dot{\theta}_{2}\right. \\
& \left.-b_{3} \dot{\theta}_{1}-\dot{y}_{1}\right)+k_{4}\left(y_{3}-y_{4}\right)+c_{4}\left(\dot{y}_{3}-\dot{y}_{4}\right)=0, \\
& m_{4} \ddot{y}_{4}+k_{4}\left(y_{4}-y_{3}\right)+c_{4}\left(\dot{y}_{4}-\dot{y}_{3}\right)=0 \text {, } \\
& m_{5} \ddot{y}_{5}+k_{5}\left(y_{5}+a_{5} \theta_{3}-y_{2}\right)+c_{5}\left(\dot{y}_{5}+a_{5} \dot{\theta}_{3}-\dot{y}_{2}\right)=0 \text {, } \\
& m_{6} \ddot{y}_{6}+k_{6}\left(y_{6}-y_{4}\right)+c_{6}\left(\dot{y}_{6}-\dot{y}_{4}\right)=0 \text {, } \\
& J_{1} \ddot{\theta}_{1}+\left[2 k_{1}\left(b_{1}-b_{2}\right)+k_{3} b_{3}\right] y_{1}+\left[2 c_{1}\left(b_{1}-b_{2}\right)+c_{3} b_{3}\right] \\
& \cdot \dot{y}_{1}-k_{3} b_{3} y_{3}-c_{3} b_{3} \dot{y}_{3}+\left[2 k_{1}\left(b_{1}{ }^{2}+b_{2}{ }^{2}\right)+k_{3} b_{3}{ }^{2}\right] \theta_{1} \\
& +\left[2 c_{1}\left(b_{1}^{2}+b_{2}{ }^{2}\right)+c_{3} b_{3}{ }^{2}\right] \dot{\theta}_{1} \\
& +\left[k_{1}\left(a_{1}-a_{2}\right)\left(b_{1}+b_{2}\right)\right] \theta_{2}+\left[c_{1}\left(a_{1}-a_{2}\right)\left(b_{1}+b_{2}\right)\right] \\
& \cdot \dot{\theta}_{2}-b_{1} k_{1}\left[\xi_{1}(t)+\xi_{2}(t)\right]-b_{1} c_{1}\left[\dot{\xi}_{1}(t)+\dot{\xi}_{2}(t)\right] \\
& +b_{2} k_{1}\left[\xi_{3}(t)+\xi_{4}(t)\right]+b_{2} c_{1}\left[\dot{\xi}_{3}(t)+\dot{\xi}_{4}(t)\right]=0, \\
& J_{2} \ddot{\theta}_{2}+\left(2 a_{2} k_{1}-2 a_{1} k_{1}-a_{3} k_{3}\right) y_{1}+\left(2 a_{2} c_{1}-2 a_{1} c_{1}\right. \\
& \left.-a_{3} c_{3}\right) \dot{y}_{1}+a_{3} k_{3} y_{3}+a_{3} c_{3} \dot{y}_{3} \\
& +\left[k_{1}\left(b_{2}-b_{1}\right)\left(a_{1}-a_{2}\right)-a_{3} b_{3} k_{3}\right] \theta_{1}
\end{aligned}
$$




$$
\begin{aligned}
& +\left[c_{1}\left(b_{2}-b_{1}\right)\left(a_{1}-a_{2}\right)-a_{3} b_{3} c_{3}\right] \dot{\theta}_{1} \\
& +\left[2 k_{1}\left(a_{1}^{2}+a_{2}^{2}\right)+a_{3}^{2} k_{3}\right] \theta_{2}+\left[2 c_{1}\left(a_{1}^{2}+a_{2}^{2}\right)\right. \\
& \left.+a_{3}^{2} c_{3}\right] \dot{\theta}_{2}+a_{1} k_{1}\left[\xi_{1}(t)+\xi_{4}(t)\right]+a_{1} c_{1}\left[\dot{\xi}_{1}(t)\right. \\
& \left.+\dot{\xi}_{4}(t)\right]-a_{2} k_{1}\left[\xi_{2}(t)+\xi_{3}(t)\right]-a_{2} c_{1}\left[\dot{\xi}_{2}(t)\right. \\
& \left.+\dot{\xi}_{3}(t)\right]=0, \\
J_{3} \ddot{\theta}_{3} & +2 k_{1}\left(a_{6}-a_{4}-a_{5} k_{5}\right) y_{2}+2 c_{1}\left(a_{6}-a_{4}-a_{5} c_{5}\right) \dot{y}_{2} \\
& +a_{5} k_{5} y_{5}+a_{5} c_{5} \dot{y}_{5}+\left[2 k_{2}\left(a_{4}{ }^{2}+a_{6}^{2}\right)+a_{5}^{2} k_{5}\right] \theta_{3} \\
& +\left[2 c_{2}\left(a_{4}^{2}+a_{6}^{2}\right)+a_{5}^{2} c_{5}\right] \dot{\theta}_{3}+a_{4} k_{2}\left[\xi_{5}(t)+\xi_{8}(t)\right] \\
& +a_{4} c_{2}\left[\dot{\xi}_{5}(t)+\dot{\xi}_{8}(t)\right]-a_{6} k_{2}\left[\xi_{6}(t)+\xi_{7}(t)\right] \\
& -a_{6} c_{2}\left[\dot{\xi}_{6}(t)+\dot{\xi}_{7}(t)\right]=0 .
\end{aligned}
$$

The matrix form of (5) is

$$
\mathbf{M} \ddot{\mathbf{y}}(t)+\mathbf{C} \dot{\mathbf{y}}(t)+\mathbf{K y}(t)=\mathbf{B}_{\mathbf{1}} \mathbf{h}_{1}(t)+\mathbf{B}_{\mathbf{2}} \mathbf{h}_{2}(t) .
$$

In the matrix equation, $\mathbf{M}, \mathbf{C}$, and $\mathbf{K}$ are the mass matrix, damping matrix, and stiffness matrix; $\mathbf{B}_{1}$ and $\mathbf{B}_{2}$ are the coefficient matrices of the unevenness function; and $\mathbf{h}_{1}(t)$ and $\mathbf{h}_{2}(t)$ are the unevenness functions of the wheels (provided in Appendix B).

3.2. Exciting Force Analysis. As (6) conveys, the main exciting forces are the exciting force of the elastic deformation of the girder on the trolley and that of rail defects on the crane cart.

3.2.1. Exciting Force of Trolley. The basis of trolley operation is that rigid motion of the crane span structure is generated by the motion of the crane cart's traveling mechanism and that elastic deformation of the crane span structure is produced by the weight of the trolley, the weight of the slung cargo, the girder's own weight, and inertia. According to the basic hypotheses, during operation of the overhead crane, a particle on the main girder experiences not only rigid motion in the $z$-axis direction but also elastic displacement in the $y$-axis direction of the global coordinate system. Figure 2 shows the main girder deformation under its own gravity and wheel pressures of trolley.

Under normal circumstances, the impact of trolley rail vibration and the impact of the deformation of the main girder on the system vibration can be ignored. The reason for this is that the trolley rail and the cart rail are different. A fullrail or a welded rail joint is typically used to ensure smoothness. Thus, the wheels of the trolley are exposed to small excitation forces that can be ignored. Because crane design specifications require that the main girder deformation be less than one thousandth of its span, crane plants usually process the main girder as an arched form (the calculation of the arch amplitude is described in literature [43]), which offsets a portion of the girder's elastic deformation due to

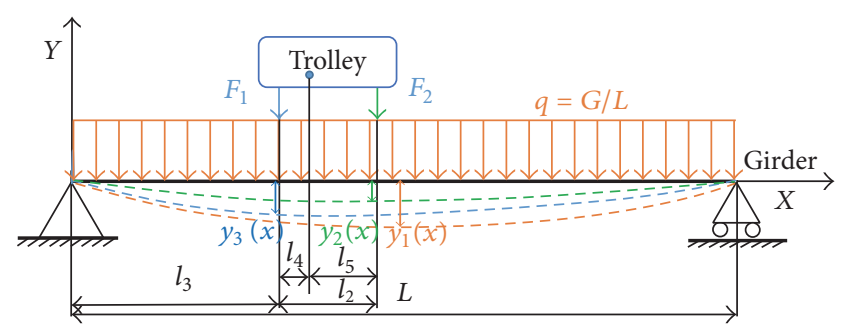

FIgURE 2: Structural diagram of the main girder deformation.

the weight of the trolley, the weight of the slung cargo, the girder's own weight, and inertia. The crane cab is positioned at the end of the main girder. The main girder deformation in $Y$ direction has little influence on the cab or the operator, so its effect can be ignored in analyzing vertical vibrations of human.

3.2.2. Analysis of Crane Runway Unevenness. Vibration caused by rail defects is analyzed without considering the effect of trolley traveling on the system vibration. Generally speaking, the crane design requires a less-than- $1 \mathrm{~mm}$ height difference at rail gaps [44]. However, the actual rail height difference may reach or exceed $4 \mathrm{~mm}$ during operation of the crane because of environmental effects on the rail foundation. On the other hand, joint gaps between rails have effects on crane operation.

The effects of hoisting machinery working on rails with height differences and gaps and dynamic loading caused by the cabin can be estimated using a suitable elastic dynamic model [43]. That is, an unevenness function is applied to express a rail height difference or gap. Figure 3 illustrates two situations in which wheels pass over rail defects (a step and a gap). Because the crane rail defects $h_{s}$ and $h_{g}$ shown in Figure 3 are much smaller than the wheel radius $r$ and because of the crane's heavy weight, the vertical displacement function of front and rear wheels caused by rail defects can be expressed as vertical displacement functions according to the variation of sine/cosine laws, as shown in Figure 4.

The approximate unevenness function $h_{1}(t)$ of the elastic dynamic model of the displacement exciting force generated when wheels pass over a gap is expressed as

$$
\begin{array}{ll}
h_{1}(t)=\frac{h_{s}}{2}\left(1-\cos \omega_{s} t\right) & 0 \leq t \leq t_{s}, \\
h_{1}(t)=\frac{h_{g}}{2}\left(1-\cos \omega_{g} t\right) & 0 \leq t \leq t_{g},
\end{array}
$$

where $\omega_{s}=\pi v / \sqrt{2 r h_{s}}, \omega_{g}=2 \pi v / e_{g}$, and $h_{g}=e_{g}{ }^{2} / 8 r$.

The unevenness function $h_{1}(t)$ gained from the above two situations is the external exciting force generated when crane wheel passes the rails. As (7) show, the unevenness function $h_{1}(t)$ depends on the height differences $h_{s}$ and $h_{g}$ of the rail defects and the rail excitation frequencies $\omega_{s}$ and $\omega_{g}$. A crane vibration system is affected not only by the unevenness function but also by the number, shapes, and sizes of the crane wheels. More wheels result in more impacts on the crane, so the impact order of the wheels on the gap must be fully 


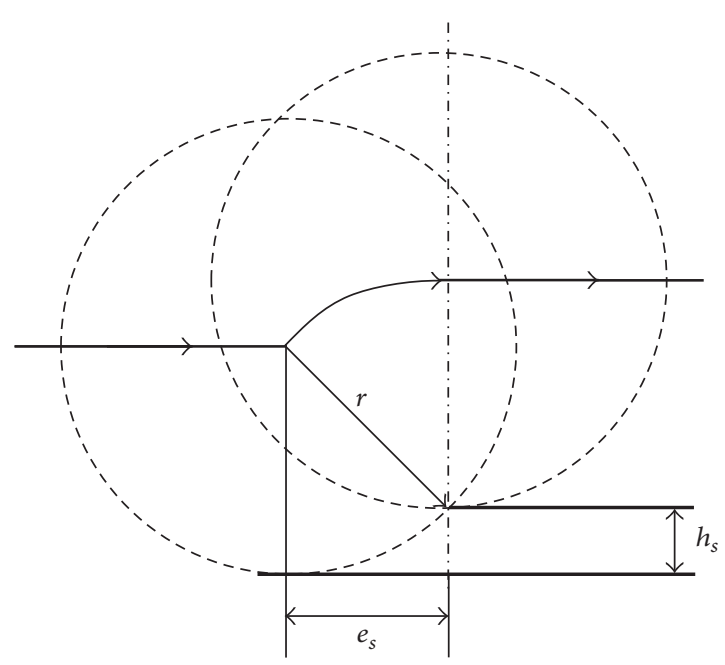

(a) Passing over a step

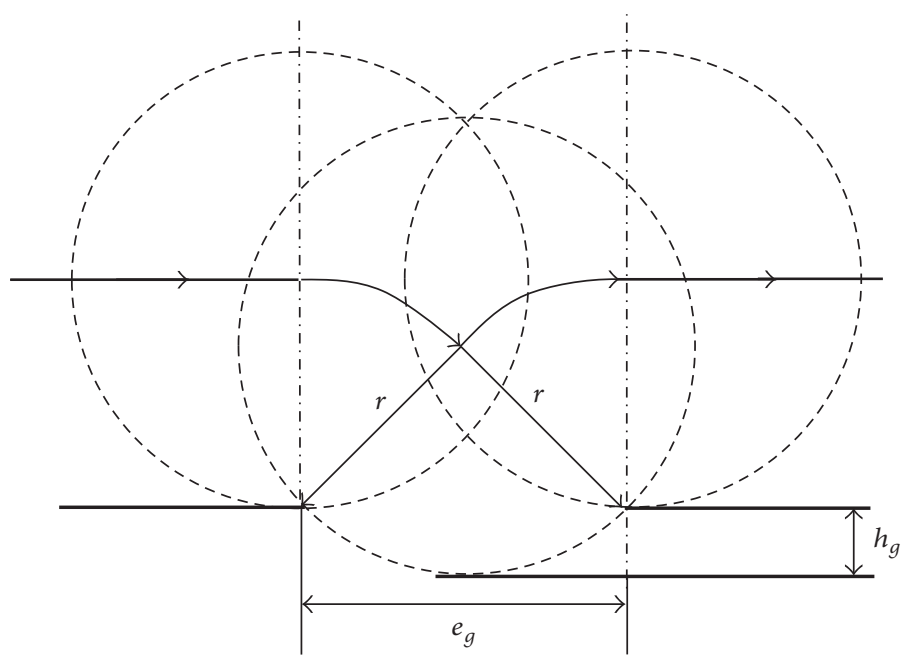

(b) Passing over a gap

FIGURE 3: Movement of wheel center.

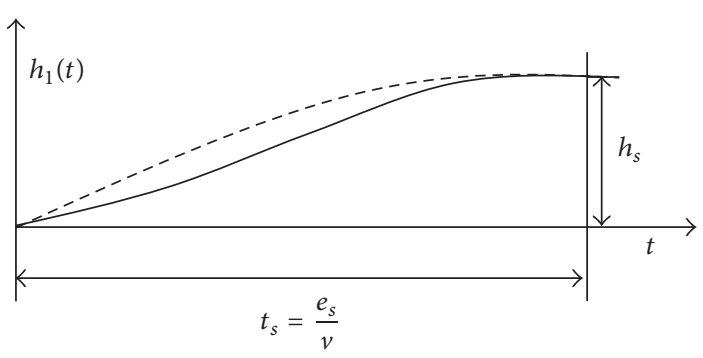

(a) Passing over a step

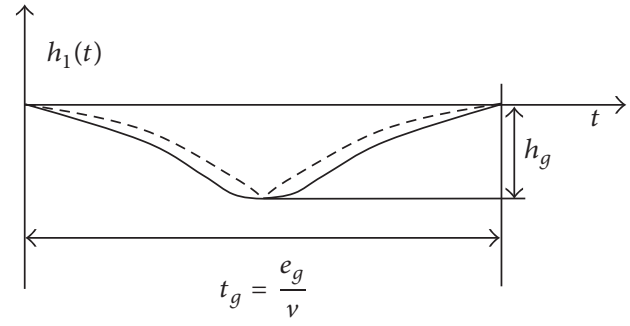

(b) Passing over a gap

FIGURE 4: Unevenness functions $h_{1}(t)$.

considered in the crane design to avoid simultaneous impacts of the wheels.

3.2.3. Numerical Results. The time-domain response of the dynamic system can be obtained using the direct integration method for a linear dynamic system with constant coefficients. Newmark method [45-47] is a typical implicit solution approach to structural dynamics problems that has the advantages of good convergence, precision, and stability. Not only is the method condition stable but its stability condition is easily satisfied.

The vibration equations mentioned in Sections 3.1 and 3.2 can be solved by Newmark method to determine the timedomain response of the dynamic system. Taking the doublegirder $100 \mathrm{t}-28.5 \mathrm{~m}$ casting crane produced by a certain enterprise as an example (the basic parameters of the design and their values are provided in Appendix A), the effects of rail defects and the cart's operating speed on human vibration were analyzed from the following two perspectives.

(1) For a constant rail defect, a height dislocation $h_{s}=$ $2 \mathrm{~mm}$, and a joint defect $e_{g}=20 \mathrm{~mm}$, the influence of crane vibration on human comfort at various crane cart running speeds was analyzed. The results are shown in Figures 5 and 6.
As Figures 5 and 6 show, the difference between the peaks of acceleration is narrow when the speed is in the range of 1.25 to $2 \mathrm{~m} / \mathrm{s}$. A larger instantaneous acceleration occurs during the process of the impact of crane wheel which is closest to the cabin. This is identical to the human body response.

(2) For a constant speed $(v=1 \mathrm{~m} / \mathrm{s})$, the relation of the vibration response of the crane structure to the vibration response of the human body and the power spectral density were analyzed for various rail defects. For height dislocations $h_{s}=1,2,3$, and $4 \mathrm{~mm}$, the results are shown in Figures 7 and 8. For rail joint defects $e_{g}=6,12,18$, and $24 \mathrm{~mm}$, the results are shown in Figures 9 and 10.

As Figures 7 and 8 show, $h_{s}$ has a considerable influence on the human body vibration acceleration. When $h_{s}=4 \mathrm{~mm}$, the maximum acceleration of the human body reaches $2.1 \mathrm{~m} / \mathrm{s}^{2}$, whereas when $h_{s}=1 \mathrm{~mm}$, the maximum acceleration is only $0.2 \mathrm{~m} / \mathrm{s}^{2}$. The human body vibration is the strongest at a frequency of $7.8 \mathrm{~Hz}$, which is consistent with the human body frequency sensitivity range of $4-8 \mathrm{~Hz}$.

As Figures 9 and 10 show, when $e_{g}=6 \mathrm{~mm}$, the peak value of the human body vibration acceleration is $0.008 \mathrm{~m} / \mathrm{s}$, and when $e_{g}=24 \mathrm{~mm}$, the peak ground acceleration is four times greater than when $e_{g}=6 \mathrm{~mm}$. The higher gap size corresponds to a level of vibration at which people "don't 


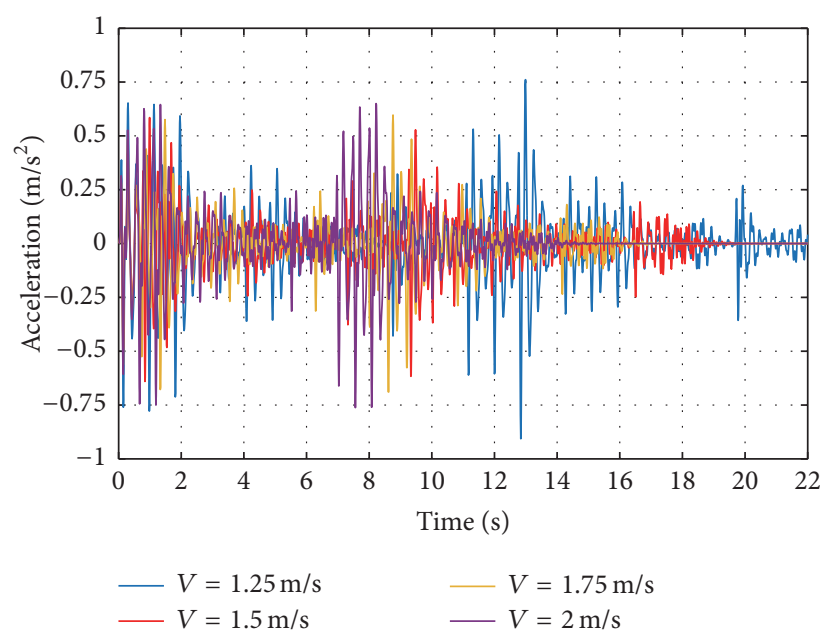

FIgURE 5: Time-domain responses of human body vibration at various velocities $\left(h_{s}=2 \mathrm{~mm}\right)$.
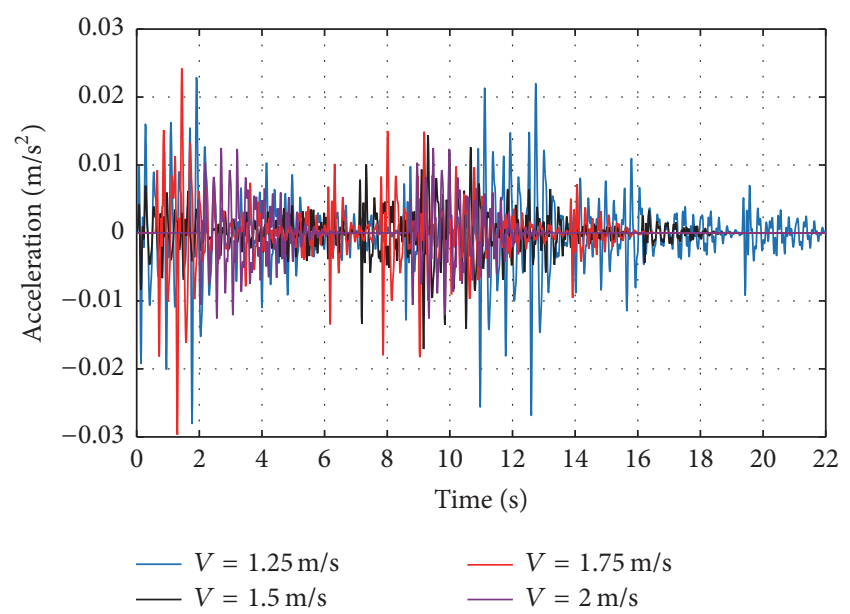

FIgURE 6: Time-domain responses of human body vibration at various velocities $\left(e_{g}=20 \mathrm{~mm}\right)$.

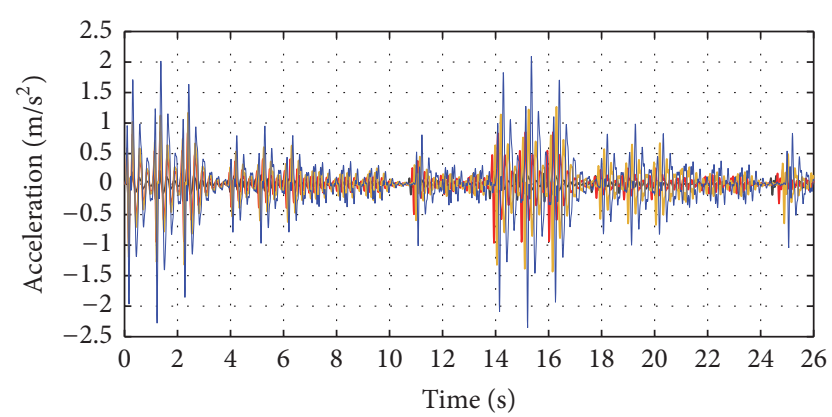

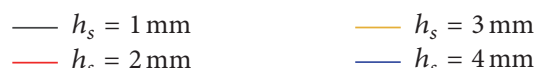

Figure 7: Time-domain response of human body vibration for various rail steps.

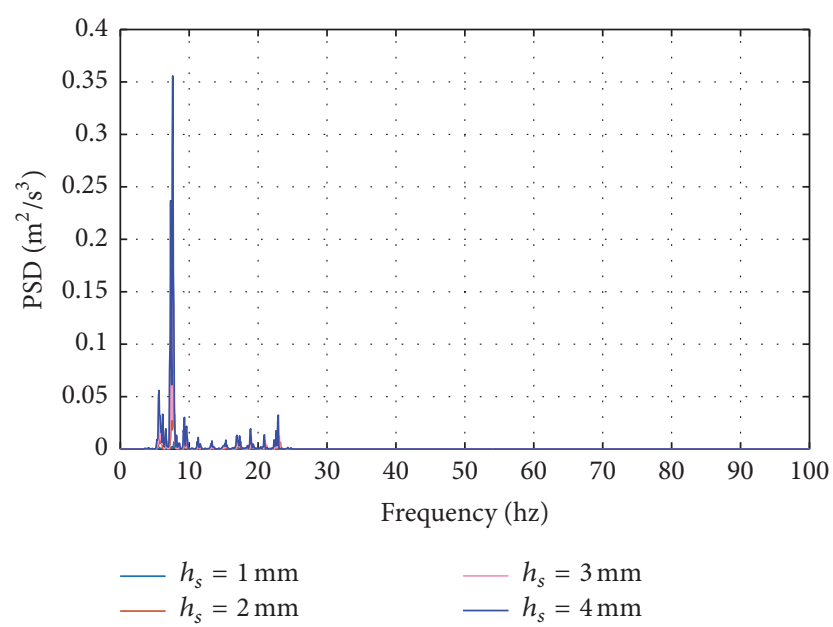

FIGURE 8: Power spectral density of human body for various rail steps.

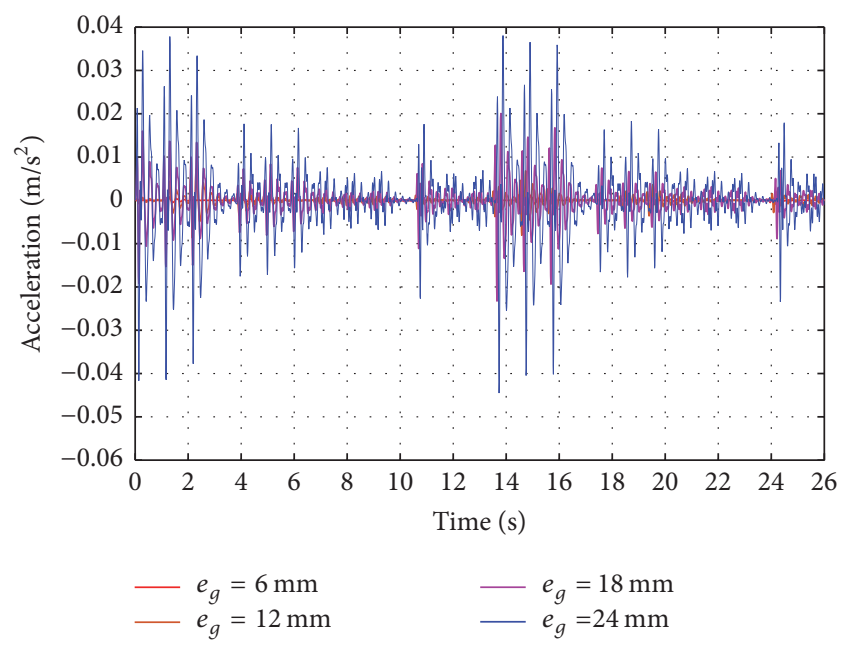

FIgURE 9: Time-domain response of human body acceleration for various gaps.

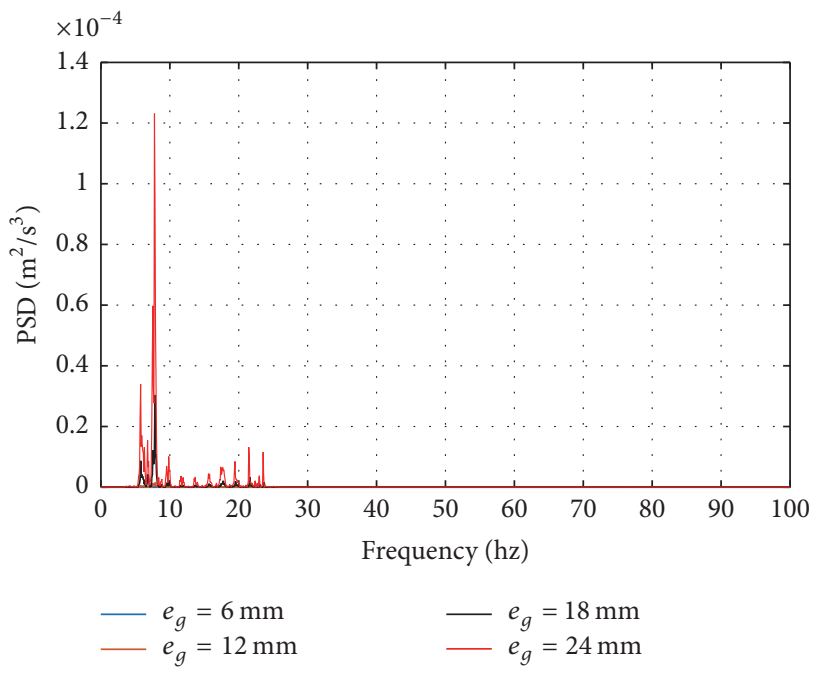

FIGURE 10: Power spectral density of human body vibration for various gaps. 


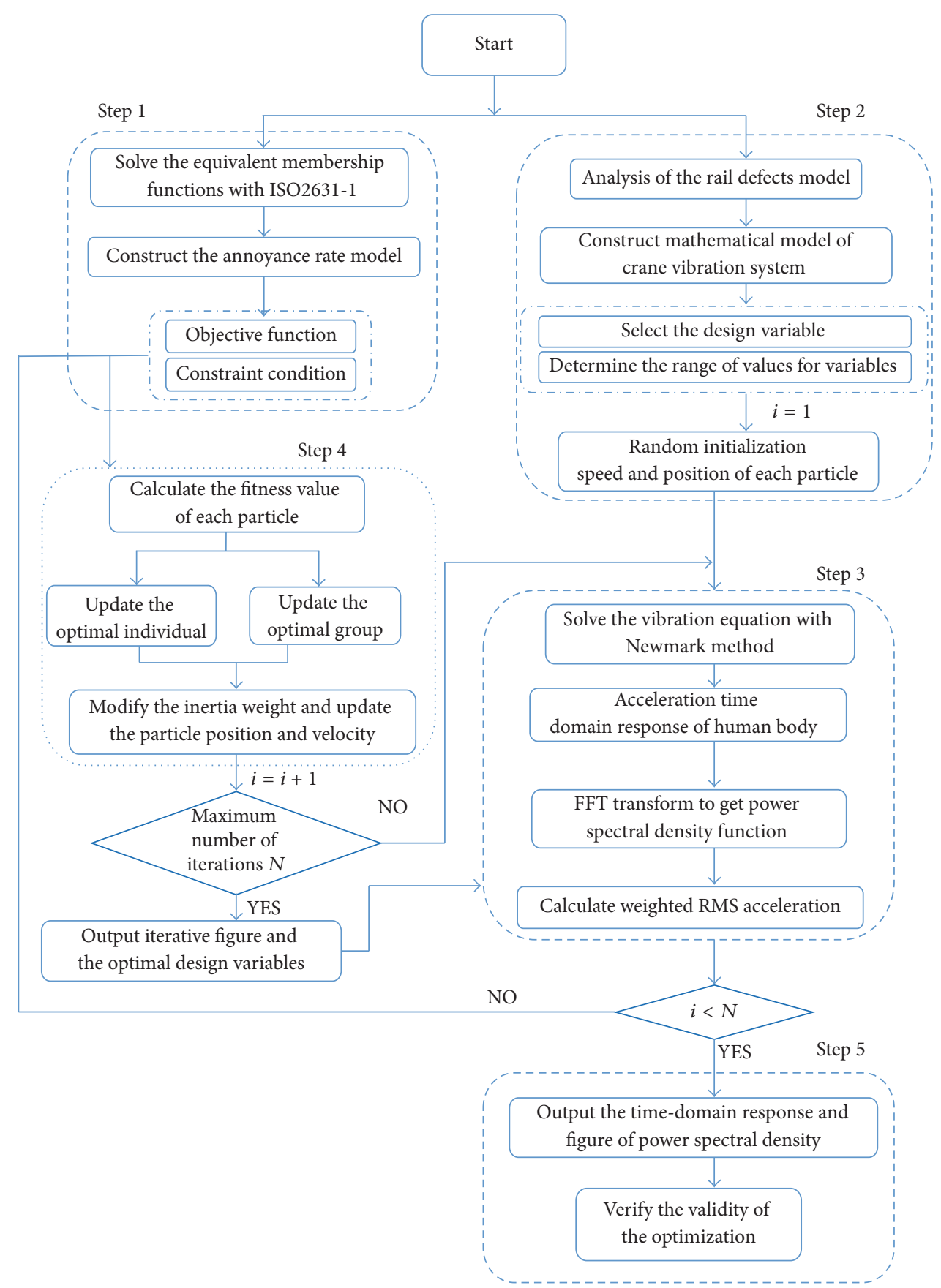

FIGURE 11: The optimization process.

feel uncomfortable," according to ISO 2631-1, so they are not tired or annoyed by the vibration. Figure 10 shows that the power spectral density of human body vibration reaches its peak when the frequency is approximately $7.8 \mathrm{~Hz}$, and a second peak appears when the frequency is approximately $6 \mathrm{~Hz}$, which means that these are the two frequencies at which people feel the strongest vibrations.

\section{Methodology}

The vibration of a double-girder $100 \mathrm{t}-28.5 \mathrm{~m}$ casting crane during its operation makes the human body feel uncomfortable. Section 3.2.3 explains that the design parameters cannot satisfy human comfort requirements in the presence of rail defects. The effect of vibration on the comfort of the operator is not considered in the early stages of the design of a crane. A procedure for optimizing the crane design with respect to human body comfort is illustrated in Figure 11. The steps in the optimization procedure are as follows:

(1) According to the ISO 2631-1 evaluation criteria, a subjective human evaluation of the membership function 
is performed. Fechner's law of psychophysics is used to establish an evaluation model for human vibration comfort as the objective function (the fitness function), which is dependent only on the root mean square (RMS) of acceleration.

(2) On the basis of the analysis of rail defects, a mathematical model of the crane vibration system is established. The ranges of values of the design variables are determined, and the PSO algorithm is used to randomly initialize the velocity and position of each particle (the design variable). At this time, iterations $i=1$.

(3) Newmark method is used to obtain the numerical solution of the mathematical model of the structural vibration system. The time-domain response of the human body acceleration is obtained, and the power spectral density function is obtained by means of a fast Fourier transform. Based on the time-domain response of human body acceleration, the RMS of the weighted acceleration of the human body vibration is obtained by the continuous weight function method, which is recommended in ISO 2631-1. If the requirements are satisfied within the maximum number of iterations $N(i<N)$, the process continues with Step (4). Until meeting the conditions $(i=N)$, the process continues with Step (5).

(4) With the acceleration amplitude and displacement amplitude of each crane combined as constraints, the fitness value of each particle is calculated to determine the optimal individual and population. On this basis, the inertial weight is modified, and the particle position and speed are updated. By this time, iterations $i=i+1$. If $i$ reach the maximum number of iterations $N$, the time-domain response map and the power spectral density map are output and back to Step (3) to obtain the human body vibration response under the optimal design variables. Otherwise replace the updated particle position and velocity into Step (3).

(5) The time-domain response map and the power spectral density map are output. The effectiveness of the optimization is then verified.

4.1. Annoyance Rate Model and Quantitative Evaluation. ISO 2631-1 identifies allowed vibration intensities $a_{w}$ for various working conditions. Depending on the value of $a_{w}$, a human's subjective response to vibration is divided into two parts, comfort and discomfort. However, this characterization is not consistent with the continuity of a person's subjective sensation, and it does not lend itself to quantitative, reliable, and optimized analysis of human discomfort associated with structural vibrations. Unlike the standard evaluation method, fuzzy assessment methods, which have also been employed by many researchers, require a number of experts to evaluate each factor. This introduces too much subjectivity. It is necessary therefore to have a better understanding of and make further improvements to the present evaluation method. In this study, the standard evaluation method was combined with an annoyance rate model to analyze crane vibration and characterize it in terms of quantization, continuity, and certainty. In addition to the merits of the standard evaluation method, this combined approach offers the advantage of producing discomfort ratios for the operators.

4.1.1. Annoyance Rate Model. The concept of an annoyance rate is drawn from psychophysics and refers to the proportion of a group of people who have an annoyance response to an input. In this case, the annoyance rate represents the proportion of people who think a vibration is unacceptable or who are annoyed at a certain vibration intensity.

The theoretic basis of the annoyance rate evaluation method is the psychophysical signal detection of processed experimental data. The annoyance rate is the basis of identification of an annoyance threshold determined by a vibration comfort standard. The annoyance threshold is the limiting value of vibration acceleration that ensures a sense of comfort. The results of an experiment conducted by Griffin and Whitham [48] in 1978 demonstrated that the distribution of human response to vibration follows a log-normal distribution. Because of the fuzziness and randomness of the subjectivity of vibration response, according to the setvalue statistical approach and the method for computing the psychological annoyance rate, the structural vibration annoyance rate under the continuous distribution can be expressed as

$$
f(x \mid u)=\frac{1}{\sqrt{2 \pi} u \sigma} \exp \left[-\frac{1}{2}\left(\frac{\ln (u)-\mu_{\ln (x)}}{\sigma}\right)^{2}\right] .
$$

In this equation, $\sigma^{2}=\ln \left(1+\delta^{2}\right), \mu_{\ln (x)}=\ln (x)-(1 / 2) \sigma^{2}$, $x$ is the expected value of $u$, and $\sigma$ is a coefficient in the range of 0.1-0.5 whose value is determined experimentally.

Equation (8) means that although different people have different responses to the vibration effect of acceleration $x$, the overall statistical average is a function of $x$.

Considering the fuzziness and randomness of the distribution, when the vibration acceleration is $x$, the annoyance formula of the continuous distribution is

$$
\begin{aligned}
& A\left(a_{w}\right) \\
& \quad=\int_{u_{\min }}^{\infty} \frac{1}{\sqrt{2 \pi} u \sigma_{\ln }} \exp \left[-\frac{1}{2}\left(\frac{\ln \left(u / a_{w}\right)+0.5 \sigma_{\ln }^{2}}{\sigma_{\ln }}\right)^{2}\right] \\
& \quad \cdot v(u) d u .
\end{aligned}
$$

In this equation, $\sigma_{\ln }^{2}=\ln \left(1+\delta^{2}\right), a_{w}$ is the vibration intensity of frequency weighting, and $v(u)$ is the fuzzy membership function of the vibration intensity.

Solving (9) requires that $a_{w}$ and $v(u)$ be solved first. Their solutions are presented in the following two sections.

4.1.2. Root Mean Square of Weighted Acceleration. Because different people are sensitive to the frequency of vibration to different degrees, the frequency component of complex random vibration is quite sophisticated. The interference 
effect of different bands on human feeling under narrowband random vibration necessitates frequency weighting of the valid vibration acceleration value of other bands besides the human range of frequency sensitivity and conversion to effective values of vibration acceleration in the range of the most sensitive frequencies, that is, determination of an effective value of weighted acceleration.

The continuous weight function recommended in ISO 2631-1 is used to determine the weighted acceleration of frequency $a_{w}(t)$ in (9). Equiband spectral analysis of the experimentally determined time history of the vibration acceleration $a_{w}(t)$ is performed so that the density function of the acceleration autopower spectrum in the frequency range $G_{a}(f)$ can be obtained. The weighted RMS of the acceleration $a_{w}$ is as follows:

$$
\begin{aligned}
& {\left[\int_{0.89}^{100} W^{2}(f) G_{a}(f) d f\right]^{1 / 2}} \\
& \quad=\left[\sum_{1}^{n} W^{2}\left(f_{i}\right) G_{a}\left(f_{i}\right) \delta f\right]^{1 / 2} .
\end{aligned}
$$

In this equation, $n$ is the number of discrete points of the power spectral density function in the range between 0.89 and $100 \mathrm{~Hz}, \delta f$ is the adjacent bandwidth of discrete points, and $W_{f i}$ is the frequency weight function, calculated as follows:

$$
W_{f i}= \begin{cases}0.5 \sqrt{f_{i}}, & \left(0.89<f_{c j} \leq 4\right) \\ 1, & \left(4<f_{i} \leq 8\right) \\ \frac{8}{f_{i}}, & \left(8<f_{i} \leq 100\right) .\end{cases}
$$

4.1.3. Fuzzy Subordinating Degree Function of Vibration Intensity. Since the form of rail defects is objective in the operation of the crane, the size and direction of the external excitations which can be induced to the cart are also constant. Human vibration mainly results from the energy transferred to the human body by external excitation, for example, the energy transferred to the human operator through the crane seat when the crane is excited by a rail defect. The core of the optimization process is to optimize the structural parameters of the vibration system, which can effectively reduce the energy delivered by external excitation, thus enhancing the subjective comfort. According to ISO 2631-1, the degree of comfort felt by the human body can be determined directly using people's subjective feelings. Maintaining the vibrations felt by the human body within a comfortable range can effectively reduce the incidence of occupational diseases. Therefore, the subjective response of the human body can be used to reflect the degree of vibration and thus to infer the possibility of occupational diseases.

Vibration intensity is assessed in terms of a person's subjective reaction to vibration and its respective acceleration range. This means that the subordinating degree function determined by signal detection theory can be defined on the basis of vibration intensity. It is therefore possible to demonstrate the relation between the subordinating degree

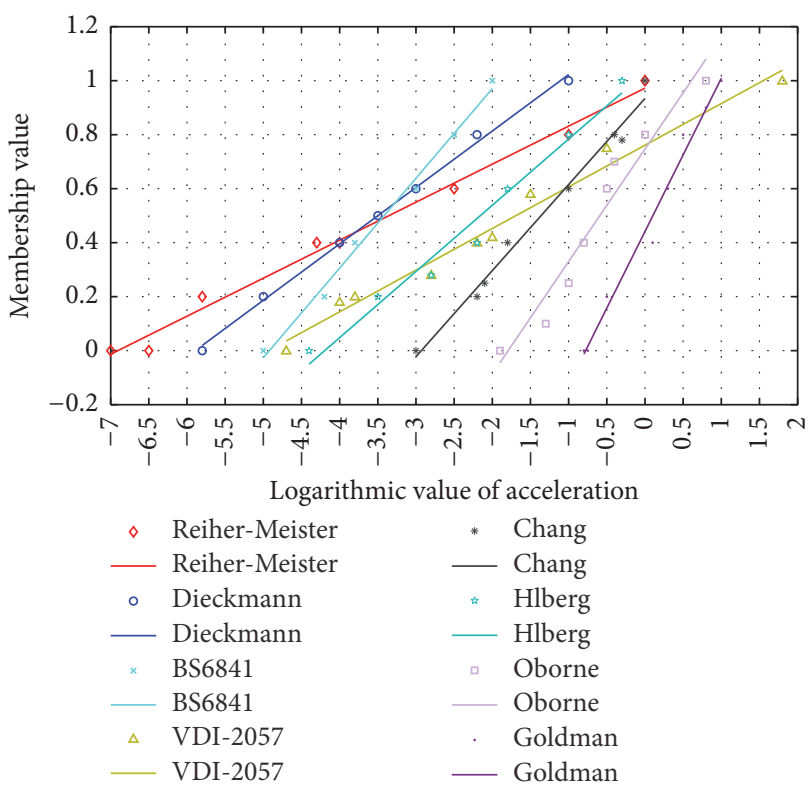

FIGURE 12: Relation between membership function and logarithmic value of acceleration.

and vibration acceleration. Figure 12 shows several groups of data frequently mentioned in the literature. Despite the large dispersion of these data, the figure shows that each group of data complies with Fechner's law, which states that the subordinating degree of the subjective reaction is directly proportional to the log of the vibration acceleration, according to the following general expression:

$$
v(u)= \begin{cases}0 & u<u_{\min } \\ \alpha \ln (u)+\beta & u_{\min } \leq u \leq u_{\max } \\ 1 & u \geq u_{\max } .\end{cases}
$$

In this expression, $u_{\min }$ is the lower limit of "vibration intense perceptive to human body"; $u_{\max }$ is the upper limit of "vibration intense bearable to human body"; and $\alpha$ and $\beta$ are coefficients whose values are undetermined and which are related as follows:

$$
\begin{aligned}
& \alpha \ln \left(u_{\text {min }}\right)+\beta=0, \\
& \alpha \ln \left(u_{\text {max }}\right)+\beta=1 .
\end{aligned}
$$

According to the ISO 2631-1 standard, when $u_{\min }=$ $0.315 \mathrm{~m} / \mathrm{s}^{2}$ and $u_{\max }=2.5 \mathrm{~m} / \mathrm{s}^{2}$, from (13), $\alpha=0.4827$ and $\beta=0.5577$. Figure 13 shows the relation between the annoyance rate and the RMS of the weighted acceleration for various values of $\delta$. Midrange values of $\delta$ (e.g., $\delta=0.3$ ) reflect more general situations.

4.1.4. Evaluation Consistency Analysis. Figure 14 is based on the ISO 2631-1 standard. The RMS of the weighted acceleration is plotted on the horizontal axis, and a discomfort scale for the human body is plotted on the vertical axis. Darker shading indicates more intense discomfort. The 


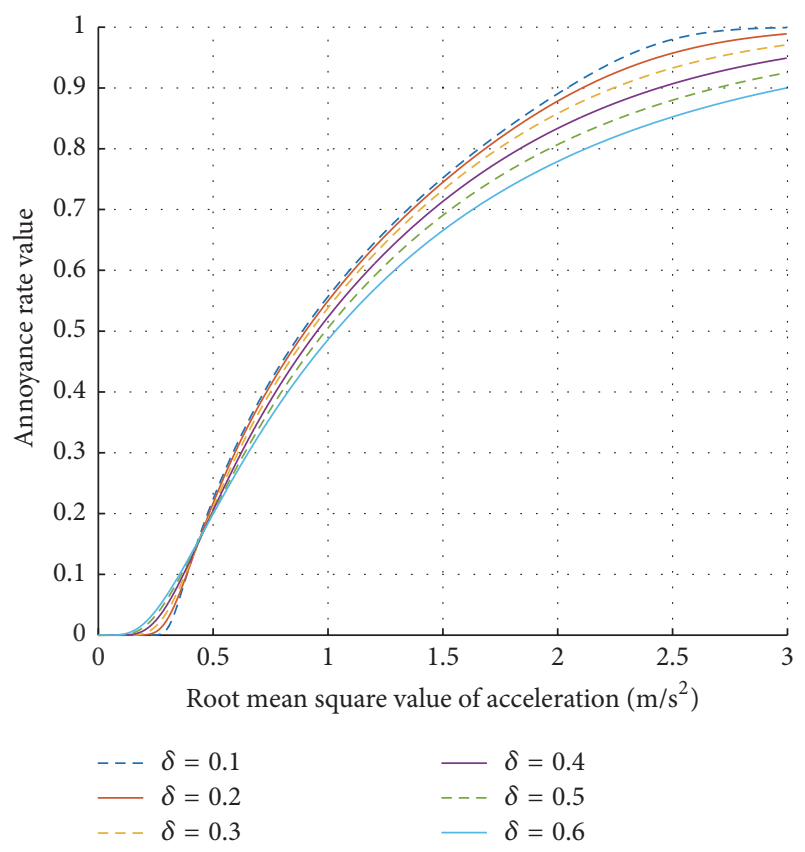

FIgURE 13: Annoyance rate curve.

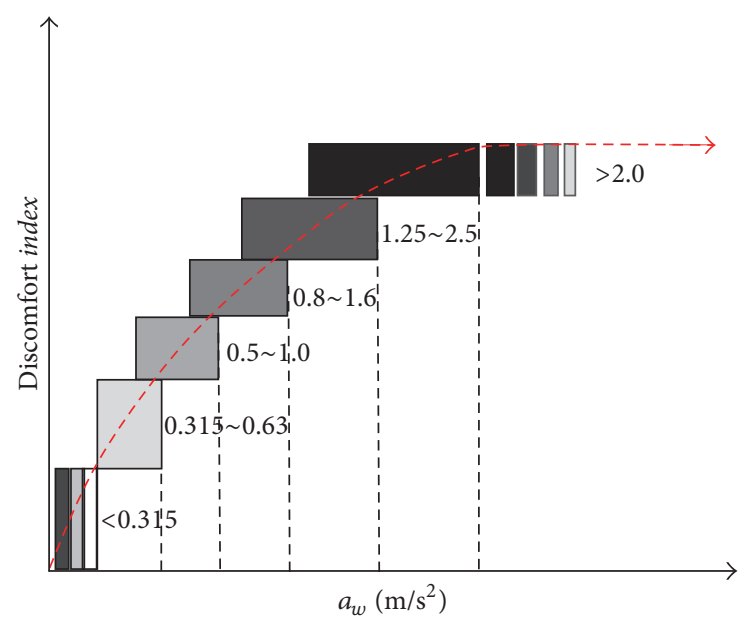

FIGURE 14: Relationship between subjective feeling and $a_{w}$.

consistency of the trends in Figures 13 and 14 confirms that the annoyance rate analysis method is consistent with the ISO 2631-1 standard evaluation method. The use of the annoyance rate method makes it possible to avoid the use of fuzzy concepts with the ISO 2631-1 standard. The proportion of people who feel discomfort at a certain vibration intensity can be confirmed quantitatively, and the relation between this proportion and the vibration acceleration of the human body can be determined. It is therefore feasible to apply the annoyance rate model to the evaluation of subjective human response to vibration.

4.2. Dynamic Optimization of the Crane Structure Based on the Annoyance Rate and PSO Algorithm. For the initial parameter values given, the RMS of the weighted acceleration is $0.59 \mathrm{~m} / \mathrm{s}^{2}$, which, according to Figure 14 , corresponds to "a little or very uncomfortable" on the discomfort scale. This indicates that the ISO 2631-1 standard cannot yield a definitive assessment of the comfort level. The corresponding annoyance rate at this acceleration is 0.283 , which means that $28.3 \%$ of people would feel uncomfortable. Of course, this level does not meet the requirements of human body comfort. However, through optimization of the crane's structural parameter values using the PSO algorithm, the annoyance rate can be lowered, and more suitable system design parameter values can be obtained.

4.2.1. Mathematical Model for Design Optimization. The mathematical model for optimization of the design is based on mathematical model described in Section 3. The model includes design variable selection, objective function definition, constraint condition identification (including constraints on the system vibration function), and the mathematical model of the optimized design.

(1) Design Variables. This optimized design uses the equivalent stiffness $k_{1}$ and structural damping $c_{1}$ of large wheels, the equivalent stiffness $k_{2}$ and structural damping $c_{2}$ of small wheels, the coupling stiffness $k_{3}$ and damping $c_{3}$ of the cabin, the stiffness $k_{4}$ and damping $c_{4}$ of the seat, the stiffness $k_{5}$ and damping $c_{5}$ of the rope, and the equivalent stiffness $k_{6}$ and damping $c_{6}$ of the human body. The set of design variables is expressed as follows:

$$
\mathbf{X}=\left(k_{1}, k_{2}, k_{3}, k_{4}, k_{5}, k_{6}, c_{1}, c_{2}, c_{3}, c_{4}, c_{5}, c_{6}\right)^{T} .
$$

(2) Objective Function. When cranes pass over rail defect, the operators' bodies experience relatively strong vibrations that can lead to occupational diseases. The literature summarized in Section 1 indicates that crane operators are more likely to suffer from occupational diseases such as LBP and that rail defects increase the vibrations sensed by operators. The objective function for meeting the human body's comfort requirement is expressed as

$$
\begin{aligned}
& f_{1}(X, t) \\
& =\int_{u_{\min }}^{\infty} \frac{1}{\sqrt{2 \pi} u \sigma_{\ln }} \exp \left[-\frac{1}{2}\left(\frac{\ln \left(u / a_{w}\right)+0.5 \sigma_{\ln }{ }^{2}}{\sigma_{\ln }}\right)^{2}\right] \\
& \cdot v(u) d u .
\end{aligned}
$$

(3) Constraint Condition. The constraint condition is the system vibration equation (6). The acceleration peak needs to be restricted to a certain range, so the following expression is included as a constraint:

$$
\max _{i=1,2, \ldots, 6}\left|\ddot{z}_{i}(t)\right| \leq \delta_{i} \text {. }
$$

In this expression, $\delta_{i}$ is the peak value of acceleration allowable at each generalized coordinate.

To satisfy the operators' comfort requirement and the performance requirements of the structure itself, the displacement amplitudes of each part must be confined within a certain range. 
The constraint for the relative displacement of crane cart wheel 1 with respect to the rail is

$$
\begin{aligned}
\xi_{1}(t)+a_{1} \theta_{2}{ }^{i}(t)-b_{1} \theta_{1}{ }^{i}(t)- & y_{1}{ }^{i}(t) \leq \varepsilon_{1}, \\
& 0 \leq t \leq T, i=1,2, \ldots, n .
\end{aligned}
$$

The constraint for the relative displacement constraint of crane cart wheel 2 with respect to the rail is

$$
\begin{aligned}
\xi_{2}(t)-b_{1} \theta_{1}^{i}(t)-a_{2} \theta_{2}^{i}(t)-y_{1}^{i}(t) \leq \varepsilon_{2}, & \\
& 0 \leq t \leq T, i=1,2, \ldots, n .
\end{aligned}
$$

The constraint for the relative displacement constraint of crane cart wheel 3 with respect to the rail is

$$
\begin{aligned}
\xi_{3}(t)+b_{2} \theta_{1}{ }^{i}(t)-y_{1}{ }^{i}(t)-a_{2} \theta_{2}{ }^{i}(t) & \leq \varepsilon_{3}, \\
& 0 \leq t \leq T, i=1,2, \ldots, n .
\end{aligned}
$$

The constraint for the relative displacement constraint of crane cart wheel 4 with respect to the rail is

$$
\begin{aligned}
\xi_{4}(t)+a_{1} \theta_{2}{ }^{i}(t)+b_{2} \theta_{1}{ }^{i}(t)- & y_{1}{ }^{i}(t) \leq \varepsilon_{4}, \\
& 0 \leq t \leq T, i=1,2, \ldots, n .
\end{aligned}
$$

The constraint for the relative displacement constraint of trolley wheel 1 with respect to the rail is

$$
\begin{aligned}
\xi_{5}(t)+a_{4} \theta_{3}{ }^{i}(t)-y_{2}{ }^{i}(t) \leq \varepsilon_{5}, & \\
& 0 \leq t \leq T, i=1,2, \ldots, n .
\end{aligned}
$$

The constraint for the relative displacement constraint of trolley wheel 2 with respect to the rail is

$$
\begin{aligned}
\xi_{6}(t)-a_{6} \theta_{3}{ }^{i}(t)-y_{2}{ }^{i}(t) \leq & \varepsilon_{6}, \\
& 0 \leq t \leq T, i=1,2, \ldots, n .
\end{aligned}
$$

The constraint for the relative displacement constraint of trolley wheel 3 with respect to the rail is

$$
\begin{aligned}
\xi_{7}(t)-a_{6} \theta_{3}{ }^{i}(t)-y_{2}{ }^{i}(t) \leq & \varepsilon_{7}, \\
& 0 \leq t \leq T, i=1,2, \ldots, n .
\end{aligned}
$$

The constraint for the relative displacement constraint of trolley wheel 4 with respect to the rail is

$$
\begin{aligned}
\xi_{8}(t)+a_{4} \theta_{3}{ }^{i}(t)-y_{2}{ }^{i}(t) \leq & \varepsilon_{8}, \\
& 0 \leq t \leq T, i=1,2, \ldots, n .
\end{aligned}
$$

The constraint for the relative displacement constraint of the cabin with respect to the crane cart is

$$
\begin{aligned}
y_{3}^{i}(t)+a_{3} \theta_{2}^{i}(t)-b_{3} \theta_{1}^{i}(t)-y_{1}^{i}(t) & \leq \varepsilon_{9} \\
& 0 \leq t \leq T, i=1,2, \ldots, n .
\end{aligned}
$$

The constraint for the relative displacement constraint of the seat with respect to the cabin is

$$
y_{4}^{i}(t)-y_{3}^{i}(t) \leq \varepsilon_{10}, \quad 0 \leq t \leq T, i=1,2, \ldots, n .
$$

The constraint for the relative displacement constraint of the rope with respect to the trolley is

$$
\begin{aligned}
y_{5}{ }^{i}(t)+a_{5} \theta_{2}^{i}(t)-y_{2}{ }^{i}(t) \leq & \varepsilon_{10}, \\
& 0 \leq t \leq T, i=1,2, \ldots, n,
\end{aligned}
$$

where $\varepsilon_{1}$ to $\varepsilon_{10}$ are the maximum relative displacements allowed.

The relative displacements in functions (17)-(27) are continuous functions of time. If $\varphi(t)$ is used as a unified representation, the constraint conditions of the above continuous functions are $\varphi(t) \leq 0$ and $0 \leq t \leq T$, and these can be shown expressed as the following constraint conditions in equivalent integral form:

$$
\int_{0}^{T}[\varphi(t)+|\varphi(t)|] d t=0 .
$$

The general formula of the unified equivalent integral is

$$
\rho_{i}=\int_{0}^{T} L_{i}[t, \mathbf{y}(t), X] d t=0 .
$$

In this formula, $L_{i}[t, \mathbf{y}(t), X]$ is the Lagrange function.

The dynamic optimization design model for crane vibration can be obtained by selection of a design variable $X$, depending on the requirements of the optimization, by minimizing (15) while meeting the constraint conditions of vibration equations (6), (16), and (29). Although the mathematical model of the dynamic optimization design is proposed based on the crane structure, it includes all of the conditions and procedures of dynamic optimization design modeling problems of the mechanical and structural systems under the transient input conditions. Because overhead crane structures are all fairly similar, the mathematical model is suitable for use in the structural dynamic optimization design of any overhead crane.

4.2.2. Particle Swarm Optimization Algorithm. In the PSO algorithm, all of the particles ( $n$ particles, e.g.) refine their spatial positions $x_{i}=\left(x_{i 1}, x_{i 2}, \ldots, x_{i d}\right)$ at velocities $v_{i}=$ $\left(v_{i 1}, v_{i 2}, \ldots, v_{i d}\right)$, and an optimal solution to the optimization problem is sought in the dimension space $d$ with a standard of fitness $F$. After every iterative search, the individual optimal solution $p_{i}=\left(p_{i 1}, p_{i 2}, \ldots, p_{i d}\right)$ of the $i$ th particle and the present optimistic solution for the whole particle group $v_{g}=\left(v_{g 1}, v_{g 2}, \ldots, v_{g d}\right)$ can be obtained. Particles refine their velocities and positions according to the following equations:

$$
\begin{aligned}
& v_{i d}^{t+1}=\omega v_{i d}^{t}+c_{1} r_{1}\left(p_{i d}^{t}-x_{i d}^{t}\right)+c_{2} r_{2}\left(p_{g d}^{t}-x_{g d}^{t}\right), \\
& x_{i d}^{t+1}=x_{i d}^{t}+v_{i d}^{t+1} .
\end{aligned}
$$

In these equations, $\omega$ is the inertia factor; $v_{i d}^{t}$ and $x_{i d}^{t}$ are the $d$-dimensional components of particle $i$ 's velocity vector 


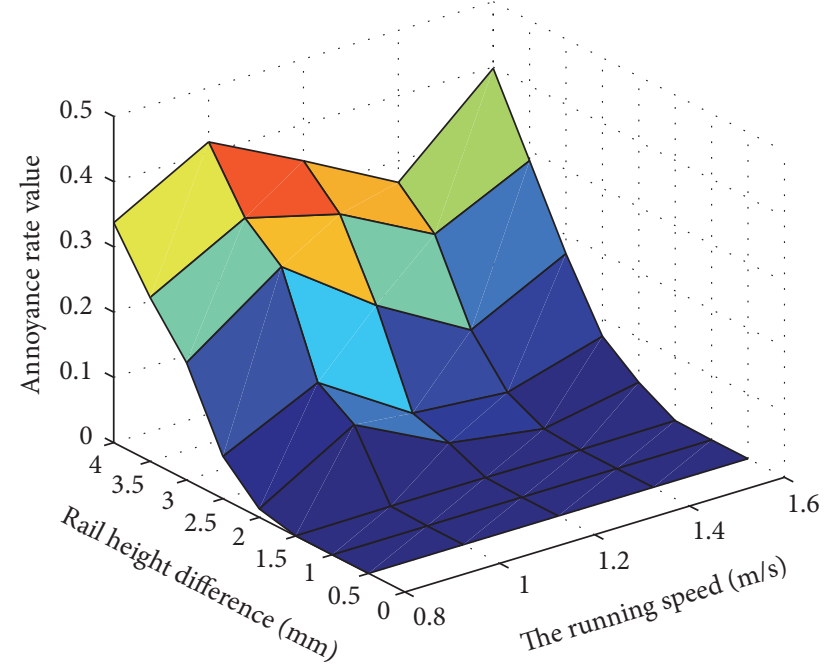

FIGURE 15: Annoyance rate versus rail height difference and running speed.

TABLE 1: RMS of weighted acceleration.

\begin{tabular}{lcccccccc}
\hline$v(\mathrm{~m} / \mathrm{s})$ & & \multicolumn{8}{c}{$h_{s}(\mathrm{~mm})$} \\
& 0.5 & 1 & 1.5 & 2 & 2.5 & 3 & 3.5 & 4.0 \\
\hline 0.8 & 0.04 & 0.09 & 0.16 & 0.25 & 0.34 & 0.47 & 0.55 & 0.66 \\
1.0 & 0.05 & 0.12 & 0.19 & 0.38 & 0.42 & $\mathbf{0 . 5 9}$ & 0.65 & 0.78 \\
1.2 & 0.05 & 0.09 & 0.19 & 0.28 & 0.31 & 0.47 & 0.60 & 0.67 \\
1.4 & 0.03 & 0.08 & 0.14 & 0.21 & 0.29 & 0.38 & 0.51 & 0.57 \\
1.6 & 0.04 & 0.09 & 0.18 & 0.29 & 0.35 & 0.46 & 0.58 & 0.75 \\
\hline
\end{tabular}

and position vector, respectively, at moment $t ; c_{1}$ and $c_{2}$ are learning factors; and $r_{1}$ and $r_{2}$ are random numbers between 0 and 1 . After the end of the iteration process, the global optimistic position $p_{g}$ is the optimal solution to the problem.

\section{Results and Discussion}

Based on the nine-degree-of-freedom mathematical model of the human-crane-rail system (Section 3) and the structural parameters of the crane (Appendix A), the RMSs of the weighted acceleration for various crane cart running speeds and rail height differences were determined and are shown in Table 1. Based on the annoyance rate model, the RMSs of the weighted acceleration were transformed into annoyance rates. The three-dimensional relationship between the annoyance rate and the rail height difference and running speed was plotted using the MATLAB software and is shown in Figure 15.

In Table 1, when $v=1 \mathrm{~m} / \mathrm{s}$ and $h_{s}=3 \mathrm{~mm}$, the largest RMS of the weighted acceleration is $0.59 \mathrm{~m} / \mathrm{s}^{2}$, and its corresponding annoyance rate is $28.3 \%$. Figure 15 shows that the annoyance rate increases linearly with the rail height difference.

Taking the structural parameters of the crane as the basic variables (the ranges of which are shown in Table 2), the operators' annoyance rate model as the objective function,
TABLE 2: Ranges of parameter values.

\begin{tabular}{lcccc}
\hline Parameters & $k_{1}(\mathrm{~N} / \mathrm{m})$ & $k_{2}(\mathrm{~N} / \mathrm{m})$ & $k_{3}(\mathrm{~N} / \mathrm{m})$ & $k_{4}(\mathrm{~N} / \mathrm{m})$ \\
\hline Minimum & $1 \times 10^{8}$ & $1 \times 10^{8}$ & $1 \times 10^{5}$ & $1 \times 10^{4}$ \\
Maximum & $5 \times 10^{8}$ & $5 \times 10^{8}$ & $1 \times 10^{6}$ & $6 \times 10^{4}$ \\
\hline Parameters & $k_{5}(\mathrm{~N} / \mathrm{m})$ & $k_{6}(\mathrm{~N} / \mathrm{m})$ & $c_{1}(\mathrm{~N} \cdot \mathrm{s} / \mathrm{m})$ & $c_{2}(\mathrm{~N} \cdot \mathrm{s} / \mathrm{m})$ \\
\hline Minimum & $5 \times 10^{8}$ & $2 \times 10^{4}$ & $6 \times 10^{4}$ & $6 \times 10^{4}$ \\
Maximum & $8 \times 10^{8}$ & $6 \times 10^{4}$ & $1 \times 10^{5}$ & $1 \times 10^{5}$ \\
\hline Parameters & $c_{3}(\mathrm{~N} \cdot \mathrm{s} / \mathrm{m})$ & $c_{4}(\mathrm{~N} \cdot \mathrm{s} / \mathrm{m})$ & $c_{5}(\mathrm{~N} \cdot \mathrm{s} / \mathrm{m})$ & $c_{6}(\mathrm{~N} \cdot \mathrm{s} / \mathrm{m})$ \\
\hline Minimum & $1 \times 10^{3}$ & $5 \times 10^{2}$ & $5 \times 10^{5}$ & $3 \times 10^{2}$ \\
Maximum & $6 \times 10^{3}$ & $1 \times 10^{3}$ & $8 \times 10^{5}$ & $2 \times 10^{3}$ \\
\hline
\end{tabular}

TABLE 3: Parameter values before and after optimization.

\begin{tabular}{lcccc}
\hline Parameters & $k_{1}(\mathrm{~N} / \mathrm{m})$ & $k_{2}(\mathrm{~N} / \mathrm{m})$ & $k_{3}(\mathrm{~N} / \mathrm{m})$ & $k_{4}(\mathrm{~N} / \mathrm{m})$ \\
\hline $\begin{array}{l}\text { Before } \\
\text { optimization }\end{array}$ & $1.15 \times 10^{8}$ & $1.06 \times 10^{8}$ & $7.65 \times 10^{5}$ & $5.27 \times 10^{5}$ \\
$\begin{array}{l}\text { After } \\
\text { optimization }\end{array}$ & $1.1 \times 10^{8}$ & $1.3 \times 10^{8}$ & $8.87 \times 10^{5}$ & $1.5 \times 10^{5}$ \\
\hline Parameters & $k_{5}(\mathrm{~N} / \mathrm{m})$ & $k_{6}(\mathrm{~N} / \mathrm{m})$ & $c_{1}(\mathrm{~N} \cdot \mathrm{s} / \mathrm{m})$ & $c_{2}(\mathrm{~N} \cdot \mathrm{s} / \mathrm{m})$ \\
\hline $\begin{array}{l}\text { Before } \\
\text { optimization }\end{array}$ & $4.87 \times 10^{8}$ & $2.17 \times 10^{4}$ & 59742 & 54691 \\
$\begin{array}{l}\text { After } \\
\text { optimization }\end{array}$ & $4.76 \times 10^{8}$ & $2.35 \times 10^{4}$ & 80741 & 50691 \\
\hline $\begin{array}{l}\text { Parameters } \\
c_{3}(\mathrm{~N} \cdot \mathrm{s} / \mathrm{m})\end{array}$ & $c_{4}(\mathrm{~N} \cdot \mathrm{s} / \mathrm{m})$ & $c_{5}(\mathrm{~N} \cdot \mathrm{s} / \mathrm{m})$ & $c_{6}(\mathrm{~N} \cdot \mathrm{s} / \mathrm{m})$ \\
\hline $\begin{array}{l}\text { Before } \\
\text { optimization }\end{array}$ & 2851 & 821 & $1.07 \times 10^{5}$ & 950 \\
$\begin{array}{l}\text { After } \\
\text { optimization }\end{array}$ & 3416 & 995 & $1.24 \times 10^{5}$ & 884 \\
\hline
\end{tabular}

and the acceleration amplitude and displacement amplitude as the constraint conditions, the PSO algorithm was used to optimize the structural parameter values. Twenty particles were selected as the initial population and the optimization results obtained after 300 iterations. Repeat this process after 50 times, and the optimal results are shown in Table 3.

As Figure 16 shows, the fitness value decreases as the iterative process progresses, eventually reaching a fitness value (annoyance value) of $9.8 \%$.

By substituting the optimized parameter values (Table 3) into (6), the relation between the time-domain response and the power spectral density of the human vibration can be obtained. The values obtained before and after optimization are shown in Figures 17 and 18.

As Figures 17 and 18 show, the human body acceleration after optimization of the crane design is significantly lower than that before optimization, as is the power spectral density. Thus, the human body vibration comfort is improved.

The scientific and practical applicability of the proposed design optimization method, based on the proposed humanvehicle-rail system model and annoyance rate model, are discussed below in terms of four items, namely, the acquisition of human vibration, acceleration response, rail defects, and human comfort.

(1) The Acquisition of Human Vibration. As Figures 5, 6, and 15 show, a crane cart's running speed has little effect on the 


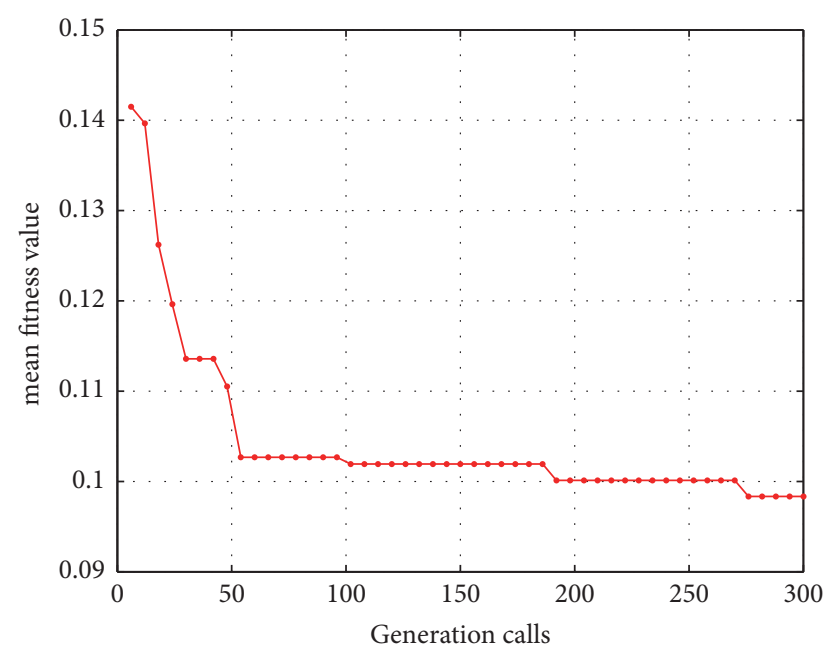

FIGURE 16: Fitness value change during optimization process.

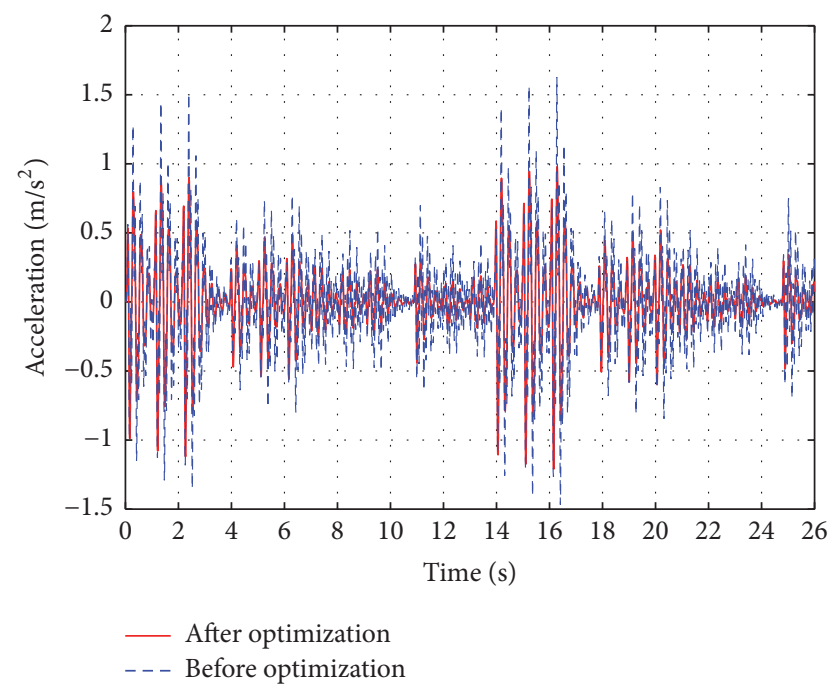

FIGURE 17: The comparison of the time-domain response of acceleration before and after optimization.

human vibration acceleration peak. Although the time of occurrence of the peak human vibration varies, the impact of the wheel nearest to the cab produces the strongest human body vibration. The reason for this is that the cab is typically located at the end of the main girder, just above the cart wheel. When the cart wheel is impacted, the force transmitted through the structure to the human body is relatively large, so the operator's body experiences the maximum acceleration. When other wheels are impacted, the vibration response of the operator's body is significantly smaller than the impact of the wheel under the cab. At the end of the impact process, the human vibration is weakened by damping.

(2) Acceleration Response. After the time-domain human body acceleration response is determined, the power spectral density function of the human body vibration is obtained by an FFT of the human vibration acceleration. The sampling frequency used in the FFT is $100 \mathrm{~Hz}$, and the number of

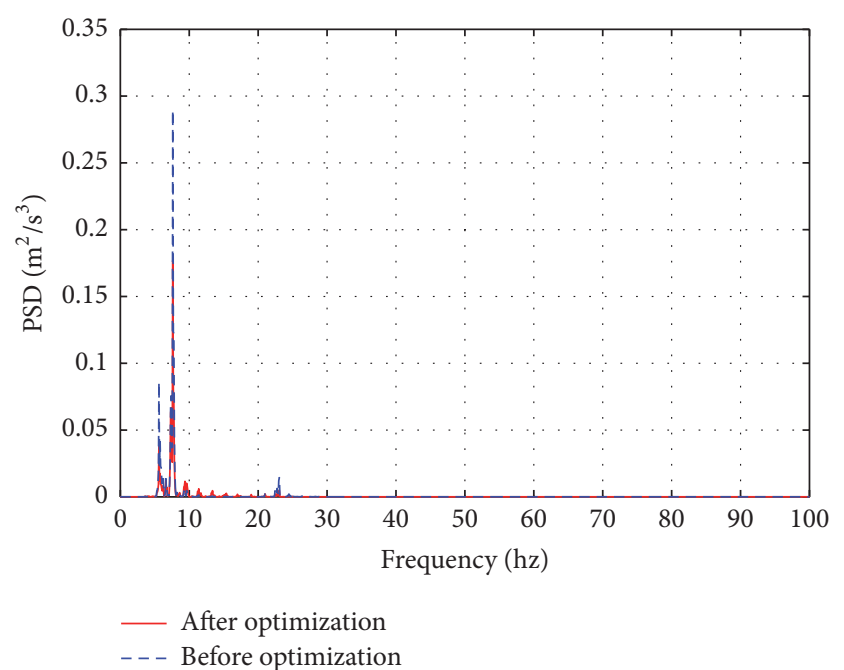

FIGURE 18: The comparison of power spectral density before and after optimization.

sampling points is 2000 , so the accuracy can be reached to $0.05 \mathrm{~Hz}$, which satisfies the requirements of human vibration analysis. The frequency response function describes the dynamic characteristics of linear system in the frequency domain and is consistent with the essential characteristics of a linear dynamic system, which are unrelated to outside stimulus sizes and types. As Figures 8, 10, and 18 show, the human body vibration is most intense at $7.8 \mathrm{~Hz}$. At $6 \mathrm{~Hz}$, the human body vibration exhibits a second peak. These results are consistent with the fact that the human resonance frequency is in the range of $4-8 \mathrm{~Hz}$.

(3) Rail Defects. Rail defects are the main sources of excitation that produce human body vibration in crane operators. As Figures 7 and 9 show, as the rail defect magnitude increases, the human body vibration increases significantly. The reason for this is that as the magnitude of rail defects increases, the impact of the rail on the wheel increases proportionally. In the system vibration model, a change in the exciting force has a strong influence on the human body vibration. Because the diameter of the wheel is much larger than the size of the rail joint defect, the vertical displacement excitation caused by defects of the rail joint is very small. The influence of rail height differences on human vibration is obviously greater than that of rail joints. Therefore, the influence of rail joint defects can be ignored in the presence of excitations which produced rail height differences.

Figures 8 and 10 show that the human power spectral density values are $0.18 \mathrm{~m}^{2} / \mathrm{s}^{3}$ a nd $0.00012 \mathrm{~m}^{2} / \mathrm{s}^{3}$ for a rail height difference of $h_{s}=3 \mathrm{~mm}$ and a joint defect $e_{g}=$ $24 \mathrm{~mm}$, respectively. In the case of a rail height difference defect, the magnitude of the acceleration vibration peak is mainly determined by the height difference of the rail joint. Therefore, to minimize the human body vibration felt by crane operators, it is important to minimize height 
differences in installation of crane rails and ensure that there is no significant deformation of the foundation under the rails. When the rail height difference is $3 \mathrm{~mm}$, the RMS of the human body weighted acceleration is $0.59 \mathrm{~m} / \mathrm{s}^{2}$. As Figure 14 shows, the corresponding human comfort rating is between "a little uncomfortable" and "very uncomfortable" but closest to "uncomfortable." It is clear that the ISO 2631-1 standard cannot precisely describe the degree of human comfort corresponding to this RMS of the weighted acceleration. This reflects the need for an accurate evaluation criterion for human comfort with respect to vibration. However, it still can be concluded from the ISO standard that the human body is not comfortable at this vibration intensity.

(4) Human Comfort. Using the PSO algorithm, the optimized values of the crane system are obtained, and these are inserted into (6) to determine the human response to the optimized system vibration. Figures 17 and 18 show comparisons of the human body vibration response before and after the optimization. As these figures show, the peak acceleration of the human body vibration was reduced from $1.7 \mathrm{~m} / \mathrm{s}^{2}$ to $0.99 \mathrm{~m} / \mathrm{s}^{2}$, a decrease of $41.7 \%$, by the optimization, and the RMS of the weighted acceleration was reduced from $0.59 \mathrm{~m} / \mathrm{s}^{2}$ to $0.38 \mathrm{~m} / \mathrm{s}^{2}$, a decrease of $55.3 \%$. The peak power spectral density was reduced from $0.28 \mathrm{~m}^{2} / \mathrm{s}^{3}$ to $0.17 \mathrm{~m}^{2} / \mathrm{s}^{3}$ at the resonant frequency of $7.8 \mathrm{~Hz}$, which means that the resonance response of the human body was significantly reduced. According to ISO2631-1 standard, which rates the human comfort from "very uncomfortable" to "slightly uncomfortable," the human comfort improved. The annoyance rate decreased from $28.3 \%$ to $9.8 \%$, which represents a significant reduction in the proportion of people who feel uncomfortable. The reason for this is that when the structural parameters of the crane are changed, the energy transmitted to the human body is reduced, and, at the same time, part of the energy is consumed by damping. The results show that design optimization can effectively reduce the human body vibration response and improve the human comfort associated with operating an overhead crane.

\section{Conclusions}

Based on the results of the study, the following conclusions can be drawn:

(1) A nine-DOF mathematical model based on vibration of the "human-crane-rail" system was developed, and it can be used to calculate the vibration response of the human body at similar kinds of work environments.

(2) A vibration comfort evaluation model for crane operation based on ISO 2631-1, namely, an annoyance rate model, is proposed. It overcomes limitations of the ISO standard in terms of its ability to precisely express the degree of human discomfort associated with certain data.

(3) The design optimization method, proposed for overhead traveling cranes, is a fast optimization method that does not depend on the failure test and test cycle, which can be used to reduce the vibration discomfort of operators associated with the vibration of the crane structure and caused by rail defects.

(4) Obtained optimization results for the crane structure parameters are consistent with operator comfort index levels. The findings provide important data reference for the design of crane parameters.

\section{Appendix}

\section{A. Systematic Parameters' Values and Meanings}

See Notations Section.

\section{B. Meanings of Matrix and Vector Quality in (6)}

$$
\begin{aligned}
& \mathbf{M}=\operatorname{diag}\left[\begin{array}{lllllllll}
m_{1} & m_{2} & m_{3} & m_{4} & m_{5} & m_{6} & J_{1} & J_{2} & J_{3}
\end{array}\right], \\
& \ddot{\mathbf{y}}=\left[\begin{array}{lllllllll}
\ddot{y}_{1} & \ddot{y}_{2} & \ddot{y}_{3} & \ddot{y}_{4} & \ddot{y}_{5} & \ddot{y}_{6} & \ddot{\theta}_{1} & \ddot{\theta}_{2} & \ddot{\theta}_{3}
\end{array}\right]^{T}, \\
& \dot{\mathbf{y}}=\left[\begin{array}{lllllllll}
\dot{y}_{1} & \dot{y}_{2} & \dot{y}_{3} & \dot{y}_{4} & \dot{y}_{5} & \dot{y}_{6} & \dot{\theta}_{1} & \dot{\theta}_{2} & \dot{\theta}_{3}
\end{array}\right]^{T}, \\
& \mathbf{y}=\left[\begin{array}{lllllllll}
y_{1} & y_{2} & y_{3} & y_{4} & y_{5} & y_{6} & \theta_{1} & \theta_{2} & \theta_{3}
\end{array}\right]^{T}, \\
& \mathbf{h}_{1}(t)=\left[\begin{array}{lllllllll}
\xi_{1} & \xi_{2} & \xi_{3} & \xi_{4} & \dot{\xi}_{1} & \dot{\xi}_{2} & \dot{\xi}_{3} & \dot{\xi}_{4}
\end{array}\right]^{T}, \\
& \mathbf{h}_{2}(t)=\left[\begin{array}{llllllll}
y_{l} & y_{r} & y_{r} & y_{l} & \dot{y}_{l} & \dot{y}_{r} & \dot{y}_{r} & \dot{y}_{l}
\end{array}\right]^{T},
\end{aligned}
$$

K

$$
=\left[\begin{array}{ccccccccc}
d_{1,1} & 0 & d_{1,3} & 0 & 0 & 0 & d_{1,7} & d_{1,8} & 0 \\
0 & d_{2,2} & 0 & 0 & d_{2,5} & 0 & 0 & 0 & d_{2,9} \\
d_{3,1} & 0 & d_{3,3} & d_{3,4} & 0 & 0 & d_{3,7} & d_{3,8} & 0 \\
0 & 0 & d_{4,3} & d_{4,4} & 0 & e_{4,6} & 0 & 0 & 0 \\
0 & d_{5,2} & 0 & 0 & d_{5,5} & 0 & 0 & d_{5,8} & d_{5,9} \\
0 & 0 & 0 & d_{6,4} & 0 & e_{6,6} & 0 & 0 & 0 \\
d_{7,1} & 0 & d_{7,3} & 0 & 0 & 0 & d_{7,7} & d_{7,8} & 0 \\
d_{8,1} & 0 & d_{8,3} & 0 & d_{8,5} & 0 & d_{8,7} & d_{8,8} & 0 \\
0 & d_{9,2} & 0 & 0 & d_{9,5} & 0 & 0 & 0 & d_{9,9}
\end{array}\right],
$$




$$
\mathbf{C}=\left[\begin{array}{ccccccccc}
e_{1,1} & 0 & e_{1,3} & 0 & 0 & 0 & e_{1,7} & e_{1,8} & 0 \\
0 & e_{2,2} & 0 & 0 & e_{2,5} & 0 & 0 & 0 & e_{2,9} \\
e_{3,1} & 0 & e_{3,3} & e_{3,4} & 0 & 0 & e_{3,7} & e_{3,8} & 0 \\
0 & 0 & e_{4,3} & e_{4,4} & 0 & e_{4,6} & 0 & 0 & 0 \\
0 & e_{5,2} & 0 & 0 & e_{5,5} & 0 & 0 & e_{5,8} & e_{5,9} \\
0 & 0 & 0 & e_{6,4} & 0 & e_{6,6} & 0 & 0 & 0 \\
e_{7,1} & 0 & e_{7,3} & 0 & 0 & 0 & e_{7,7} & e_{7,8} & 0 \\
e_{8,1} & e_{8,2} & e_{8,3} & 0 & e_{8,5} & 0 & e_{8,7} & e_{8,8} & 0 \\
0 & e_{9,2} & 0 & 0 & e_{9,5} & 0 & 0 & 0 & e_{9,9}
\end{array}\right] .
$$

In the matrices,

$$
\begin{aligned}
& d_{1,1}=4 k_{1}+k_{3}, \\
& d_{1,3}=d_{3,1}=-k_{3} \text {, } \\
& d_{1,7}=2 k_{1}\left(b_{1}-b_{2}\right) \text {; } \\
& d_{1,8}=d_{8,1}=2 a_{2} k_{1}-2 a_{1} k_{1}-a_{3} k_{3} \text {; } \\
& d_{2,2}=4 k_{2}+k_{5} \text {; } \\
& d_{2,5}=d_{5,2}=-k_{5} \text {; } \\
& d_{2,9}=d_{9,2}=2 k_{1}\left(a_{6}-a_{4}-a_{5} k_{5}\right) ; \\
& d_{3,3}=k_{3}+k_{4} \text {; } \\
& d_{3,4}=d_{4,3}=-k_{4} \text {; } \\
& d_{3,7}=d_{7,3}=-b_{3} k_{3} \text {; } \\
& d_{3,8}=d_{8,3}=a_{3} k_{3} ; \\
& d_{4,4}=k_{4} \text {; } \\
& d_{4,6}=d_{6,4}=-k_{6} \text {; } \\
& d_{5,5}=k_{5} \text {; } \\
& d_{5,9}=d_{9,5}=a_{5} k_{5} \text {; } \\
& d_{6,6}=k_{6} \text {; } \\
& d_{7,7}=2 k_{1}\left(b_{1}{ }^{2}+b_{2}{ }^{2}\right)+k_{3} b_{3}{ }^{2} ; \\
& d_{7,8}=d_{8,7}=k_{1}\left(b_{2}-b_{1}\right)\left(a_{1}-a_{2}\right)-a_{3} b_{3} k_{3} \text {; } \\
& d_{8,8}=2 k_{1}\left(a_{1}^{2}+a_{2}^{2}\right)+a_{3}^{2} k_{3} \text {; } \\
& d_{9,9}=2 k_{2}\left(a_{4}^{2}+a_{6}^{2}\right)+a_{5}^{2} k_{5} \text {; } \\
& e_{1,1}=4 c_{1}+c_{3} ; \\
& e_{1,3}=e_{3,1}=-c_{3} \text {; } \\
& e_{1,7}=e_{7,1}=2 c_{1}\left(b_{1}-b_{2}\right) \text {; } \\
& e_{1,8}=e_{8,1}=2 a_{2} c_{1}-2 a_{1} c_{1}-a_{3} c_{3} ; \\
& e_{2,2}=4 c_{2}+c_{5} \text {; } \\
& e_{2,5}=e_{5,2}=-c_{5} ; \\
& e_{2,9}=e_{9,2}=2 c_{1}\left(a_{6}-a_{4}-a_{5} c_{5}\right) ; \\
& e_{3,3}=c_{3}+c_{4} ;
\end{aligned}
$$

$$
\begin{aligned}
& e_{3,4}=e_{4,3}=-c_{4} \text {; } \\
& e_{3,7}=e_{7,3}=-b_{3} c_{3} \text {; } \\
& e_{3,8}=e_{8,3}=a_{3} c_{3} \\
& e_{4,4}=c_{4} \text {; } \\
& e_{4,6}=e_{6,4}=-c_{6} \text {; } \\
& e_{5,5}=c_{5} \\
& e_{5,9}=e_{9,5}=a_{5} c_{5} ; \\
& e_{6,6}=c_{6} \\
& e_{7,7}=2 c_{1}\left(b_{1}^{2}+b_{2}^{2}\right)+c_{3} b_{3}^{2} ; \\
& e_{7,8}=e_{8,7}=c_{1}\left(b_{2}-b_{1}\right)\left(a_{1}-a_{2}\right)-a_{3} b_{3} c_{3} ; \\
& e_{8,8}=2 c_{1}\left(a_{1}^{2}+a_{2}^{2}\right)+a_{3}^{2} c_{3} \text {; } \\
& e_{9,9}=2 c_{2}\left(a_{4}^{2}+a_{6}^{2}\right)+a_{5}^{2} c_{5} \text {; } \\
& =\left[\begin{array}{cccccccc}
k_{1} & k_{1} & k_{1} & k_{1} & c_{1} & c_{1} & c_{1} & c_{1} \\
0 & 0 & 0 & 0 & 0 & 0 & 0 & 0 \\
0 & 0 & 0 & 0 & 0 & 0 & 0 & 0 \\
0 & 0 & 0 & 0 & 0 & 0 & 0 & 0 \\
0 & 0 & 0 & 0 & 0 & 0 & 0 & 0 \\
0 & 0 & 0 & 0 & 0 & 0 & 0 & 0 \\
b_{1} k_{1} & b_{1} k_{1} & -b_{2} k_{1} & -b_{2} k_{1} & b_{1} c_{1} & b_{1} c_{1} & -b_{2} c_{1} & -b_{2} c_{1} \\
-a_{1} k_{1} & a_{2} k_{1} & a_{2} k_{1} & -a_{1} k_{1} & -a_{1} c_{1} & a_{2} c_{1} & a_{2} c_{1} & -a_{1} c_{1} \\
0 & 0 & 0 & 0 & 0 & 0 & 0 & 0
\end{array}\right],
\end{aligned}
$$

$\mathrm{B}_{2}$

$$
=\left[\begin{array}{cccccccc}
0 & 0 & 0 & 0 & 0 & 0 & 0 & 0 \\
k_{2} & k_{2} & k_{2} & k_{2} & c_{2} & c_{2} & c_{2} & c_{2} \\
0 & 0 & 0 & 0 & 0 & 0 & 0 & 0 \\
0 & 0 & 0 & 0 & 0 & 0 & 0 & 0 \\
0 & 0 & 0 & 0 & 0 & 0 & 0 & 0 \\
0 & 0 & 0 & 0 & 0 & 0 & 0 & 0 \\
0 & 0 & 0 & 0 & 0 & 0 & 0 & 0 \\
0 & 0 & 0 & 0 & 0 & 0 & 0 & 0 \\
-a_{4} k_{2} & a_{6} k_{2} & a_{6} k_{2} & -a_{4} k_{2} & -a_{4} c_{2} & a_{6} c_{2} & a_{6} c_{2} & -a_{4} c_{2}
\end{array}\right] .
$$

\section{Notations}

$$
\begin{aligned}
& m_{1}: \text { Crane cart quality }(77916(\mathrm{~kg})) \\
& m_{2}: \text { Crane trolley quality }(21000(\mathrm{~kg})) \\
& m_{3}: \text { The cabin quality }(1500(\mathrm{~kg})) \\
& m_{4}: \text { The seat quality }(80(\mathrm{~kg})) \\
& m_{5}: \text { Payload quality }(0-100000(\mathrm{~kg})) \\
& m_{6}: \text { Human body quality }(50(\mathrm{~kg})) \\
& J_{1}: \text { The rotational inertia of the crane cart } \\
& \text { around } x \text {-axis }\left(1.73 \times 10^{6}\left(\mathrm{~kg} \cdot \mathrm{m}^{2}\right)\right)
\end{aligned}
$$


$J_{2}$ : The rotational inertia of the crane cart around $z$-axis $\left(1.48 \times 10^{6}\left(\mathrm{~kg} \cdot \mathrm{m}^{2}\right)\right)$

$J_{3}$ : The rotational inertia of the trolley around $z$-axis $\left(4.16 \times 10^{4}\left(\mathrm{~kg} \cdot \mathrm{m}^{2}\right)\right)$

$k_{1}$ : The equivalent vertical rigidity of one wheel of the crane cart $\left(1.15 \times 10^{8}(\mathrm{~N} / \mathrm{m})\right)$

$k_{2}$ : The equivalent vertical rigidity of the trolley $\left(1.06 \times 10^{8}(\mathrm{~N} / \mathrm{m})\right)$

$k_{3}$ : The connecting equivalent rigidity of the cab $\left(8.87 \times 10^{5}(\mathrm{~N} / \mathrm{m})\right)$

$k_{4}$ : The vertical rigidity of the seat $\left(5.27 \times 10^{4}(\mathrm{~N} / \mathrm{m})\right)$

$k_{5}$ : The tensile rigidity of the rope $\left(4.87 \times 10^{8}(\mathrm{~N} / \mathrm{m})\right)$

$k_{6}$ : The equivalent vertical rigidity of the sitting posture $\left(2.17 \times 10^{4}(\mathrm{~N} / \mathrm{m})\right)$

$c_{1}$ : Structural damping of the crane cart $\left(5.97 \times 10^{4}(\mathrm{~N} \cdot \mathrm{s} / \mathrm{m})\right)$

$c_{2}$ : Structural damping of the trolley $\left(5.47 \times 10^{4}(\mathrm{~N} \cdot \mathrm{s} / \mathrm{m})\right)$

$c_{3}$ : Structural damping of the cab $(3416(\mathrm{~N} \cdot \mathrm{s} / \mathrm{m}))$

$c_{4}$ : Structural damping of the crane cart $(821(\mathrm{~N} \cdot \mathrm{s} / \mathrm{m}))$

$c_{5}$ : Structural damping of the rope $\left(1.24 \times 10^{5}(\mathrm{~N} \cdot \mathrm{s} / \mathrm{m})\right)$

$c_{6}$ : Structural damping of human body $(884(\mathrm{~N} \cdot \mathrm{s} / \mathrm{m}))$

$a_{1}$ : The distance in the $X$-direction from the crane cart centroid $O_{1}$ to the end beam 1 $(12.8(\mathrm{~m}))$

$a_{2}$ : The distance in the $X$-direction from the crane cart centroid $O_{1}$ to the end beam 2 $(15.7(\mathrm{~m}))$

$a_{3}$ : The distance in the $X$-direction from the cabin suspension center $\mathrm{O}_{3}$ to the crane cart centroid $O_{1}(10.8(\mathrm{~m}))$

$a_{4}$ : The distance in the $X$-direction from the trolley $\mathrm{O}_{2}$ to the front end of the trolley $(2.1(\mathrm{~m}))$

$a_{5}$ : The distance in the $X$-direction from the rope suspension center $\mathrm{O}_{5}$ to $\mathrm{O}_{2}(0.5(\mathrm{~m}))$

$a_{6}$ : The distance in the $X$-direction from the trolley centroid $\mathrm{O}_{2}$ to the trolley rear end (3.2(m))

$b_{1}$ : The distance from the crane cart centroid to girdle $1(4.9(\mathrm{~m}))$

$b_{2}$ : The distance from the crane cart centroid to girdle $1(5.2(\mathrm{~m}))$

$b_{3}$ : The distance from the cart centroid $O_{1}$ to the cabin suspension center $\mathrm{O}_{3}(1.5(\mathrm{~m}))$

$b_{4}$ : The distance in the $Z$-direction from the trolley centroid $\mathrm{O}_{2}$ to the right end of the trolley $(3.1(\mathrm{~m}))$

$b_{5}$ : The distance from the rope suspension center $\mathrm{O}_{5}$ to the trolley centroid $\mathrm{O}_{2}$ $(0.5(\mathrm{~m}))$ $b_{6}$ : The distance in the $Z$-direction from the trolley centroid $\mathrm{O}_{2}$ to the trolley left end $(3.1(\mathrm{~m}))$

$\xi_{i}(t)$ : Carts and trolleys are subject to rail incentives (variable parameter)

$\theta_{1}$ : Angular displacement of the cart around the Xaxis (variable parameter)

$\theta_{2}$ : Angular displacement of the cart around the $z$ axis (variable parameter)

$\theta_{3}$ : Angular displacement of the trolley around the zaxis (variable parameter).

\section{Competing Interests}

The authors declare that they have no competing interests.

\section{Acknowledgments}

This work has been partly funded by Postgraduate Innovation Project in Shanxi Province. The data of this work is provided by Taiyuan Heavy Industry Co., Ltd.

\section{References}

[1] J. L. Kelsey and R. J. Hardy, "Driving of motor vehicles as a risk factor for acute herniated lumbar intervertebral DISC," American Journal of Epidemiology, vol. 102, no. 1, pp. 63-73, 1975.

[2] Y. Xu, E. Bach, and E. Ørhede, "Work environment and low back pain: the influence of occupational activities," Occupational and Environmental Medicine, vol. 54, no. 10, pp. 741-745, 1997.

[3] S. Schwarze, G. Notbohm, H. Dupuis, and E. Härtung, "Doseresponse relationships between whole-body vibration and lumbar disk disease-a field study on 388 drivers of different vehicles," Journal of Sound and Vibration, vol. 215, no. 4, pp. 613628, 1998.

[4] M. Bovenzi, I. Pinto, and N. Stacchini, "Low back pain in port machinery operators," Journal of Sound and Vibration, vol. 253, no. 1, pp. 3-20, 2002.

[5] M. Bovenzi, "A longitudinal study of low back pain and daily vibration exposure in professional drivers," Industrial Health, vol. 48, no. 5, pp. 584-595, 2010.

[6] P. K. Ray and V. K. Tewari, "Ergonomic design of crane cabins: a case study from a steel plant in India," Work, vol. 41, no. 1, pp. 5972-5976, 2012.

[7] D. Grogan, R. Wells, and J. Dalton, "The health effects of whole body vibration on overhead crane operators," in Proceedings of the Human Factors Association of Canada, vol. 25, p. 277, Human Factors Association of Canada, 1992.

[8] P. M. Bongers, H. C. Boshuizen, C. T. J. Hulshof, and A. P. Koemeester, "Back disorders in crane operators exposed to whole-body vibration," International Archives of Occupational and Environmental Health, vol. 60, no. 2, pp. 129-137, 1988.

[9] P. M. Bongers, C. T. J. Hulshof, L. Dljkstra, H. C. Boshuizen, H. J. M. Groenhout, and E. Valken, "Back pain and exposure to whole body vibration in helicopter pilots," Ergonomics, vol. 33, no. 8, pp. 1007-1026, 1990.

[10] A. Burdorf and H. Zondervan, "An epidemiological study of low-back pain in crane operators," Ergonomics, vol. 33, no. 8, pp. 981-987, 1990. 
[11] A. Burdorf, B. Naaktgeboren, and H. C. W. M. de Groot, "Occupational risk factors for low back pain among sedentary workers," Journal of Occupational Medicine, vol. 35, no. 12, pp. 1213-1220, 1993.

[12] S. Piccinni, T. Marchi, A. Lorusso, and G. Magarotto, "The prevalence of spondylopathies among the crane operators in the port of Venice," La Medicina Del Lavoro, vol. 83, no. 2, pp. 146$149,1992$.

[13] M. Euler and U. Kuhlmann, "Crane runways-fatigue evaluation of crane rail welds using local concepts," International Journal of Fatigue, vol. 33, no. 8, pp. 1118-1126, 2011.

[14] Ž. Domazet, F. Lukša, and M. Bugarin, "Failure of two overhead crane shafts," Engineering Failure Analysis, vol. 44, pp. 125-135, 2014.

[15] G. P. Raymond, "Failure and reconstruction of a gantry crane ballasted track," Canadian Geotechnical Journal, vol. 38, no. 3, pp. 507-529, 2001.

[16] J. Kulka, M. Mantic, G. Fedorko, and V. Molnar, "Analysis of crane track degradation due to operation," Engineering Failure Analysis, vol. 59, pp. 384-395, 2016.

[17] P. Rettenmeier, E. Roos, S. Weihe, and X. Schuler, "Assessment of mixed mode crack propagation of crane runway girders subjected to cyclic loading," Engineering Fracture Mechanics, vol. 153, pp. 11-24, 2016.

[18] International Organization of Standardization ISO, "Mechanical vibration and shock-evaluation of human exposure to whole-body vibration - part 1: general requirements," ISO 26311, ISO, Geneva, Switzerland, 2011.

[19] D. C. D. Oguamanam, J. S. Hansen, and G. R. Heppler, "Dynamic response of an overhead crane system," Journal of Sound and Vibration, vol. 213, no. 5, pp. 889-906, 1998.

[20] J. Huang, Z. Liang, and Q. Zang, "Dynamics and swing control of double-pendulum bridge cranes with distributedmass beams," Mechanical Systems \& Signal Processing, vol. 5455, pp. 357-366, 2015.

[21] E. M. Abdel-Rahman and A. H. Nayfeh, "Two-dimensional control for ship-mounted cranes: a feasibility study," JVC/Journal of Vibration and Control, vol. 9, no. 12, pp. 1327-1342, 2003.

[22] Z. N. Masoud, A. H. Nayfeh, and N. A. Nayfeh, "Sway reduction on quay-side container cranes using delayed feedback controller: simulations and experiments," Journal of Vibration and Control, vol. 11, no. 8, pp. 1103-1122, 2005.

[23] Z. N. Masoud and A. H. Nayfeh, "Sway reduction on container cranes using delayed feedback controller," Nonlinear Dynamics, vol. 34, no. 3-4, pp. 347-358, 2003.

[24] J.-J. Wu, "Transverse and longitudinal vibrations of a frame structure due to a moving trolley and the hoisted object using moving finite element," International Journal of Mechanical Sciences, vol. 50, no. 4, pp. 613-625, 2008.

[25] N. D. Zrnić, V. M. Gašić, and S. M. Bošnjak, "Dynamic responses of a gantry crane system due to a moving body considered as moving oscillator," Archives of Civil and Mechanical Engineering, vol. 15, no. 1, pp. 243-250, 2015.

[26] O. Caglayan, K. Ozakgul, O. Tezer, and E. Uzgider, "Fatigue life prediction of existing crane runway girders," Journal of Constructional Steel Research, vol. 66, no. 10, pp. 1164-1173, 2010.

[27] P. Rettenmeier, E. Roos, and S. Weihe, "Fatigue analysis of multiaxially loaded crane runway structures including welding residual stress effects," International Journal of Fatigue, vol. 82, pp. 179-187, 2016.
[28] J. Kulka, M. Mantic, G. Fedorko, and V. Molnar, "Failure analysis of increased rail wear of 200 tons foundry crane track," Engineering Failure Analysis, vol. 67, pp. 1-14, 2016.

[29] C. Klinger, "Failures of cranes due to wind induced vibrations," Engineering Failure Analysis, vol. 43, pp. 198-220, 2014.

[30] D. C. D. Oguamanam, J. S. Hansen, and G. R. Heppler, "Dynamics of a three-dimensional overhead crane system," Journal of Sound and Vibration, vol. 242, no. 3, pp. 411-426, 2001.

[31] International Organization of Standardization, "Mechanical vibration and shock-evaluation of human exposure to wholebody vibration - part 1: general requirements," ISO 2631-1, ISO, Geneva, Switzerland, 2011.

[32] G. S. Paddan and M. J. Griffin, "Evaluation of whole-body vibration in vehicles," Journal of Sound and Vibration, vol. 253, no. 1, pp. 195-213, 2002.

[33] G. S. Paddan and M. J. Griffin, "Effect of seating on exposures to whole-body vibration in vehicles," Journal of Sound \& Vibration, vol. 253, no. 1, pp. 215-241, 2002.

[34] T. H. Langer, M. K. Ebbesen, and A. Kordestani, "Experimental analysis of occupational whole-body vibration exposure of agricultural tractor with large square baler," International Journal of Industrial Ergonomics, vol. 47, pp. 79-83, 2015.

[35] Y. Zhou and S. Chen, "Vehicle ride comfort analysis with wholebody vibration on long-span bridges subjected to crosswind," Journal of Wind Engineering and Industrial Aerodynamics, vol. 155, pp. 126-140, 2016.

[36] Y. Yang, W. Ren, L. Chen, M. Jiang, and Y. Yang, "Study on ride comfort of tractor with tandem suspension based on multibody system dynamics," Applied Mathematical Modelling, vol. 33, no. 1, pp. 11-33, 2009.

[37] S.-L. Tung, Y.-T. Juang, W.-H. Lee, W.-Y. Shieh, and W.-Y. $\mathrm{Wu}$, "Optimization of the exponential stabilization problem in active suspension system using PSO," Expert Systems with Applications, vol. 38, no. 11, pp. 14044-14051, 2011.

[38] X. Zhang, R. X. Gao, R. Yan, X. Chen, C. Sun, and Z. Yang, "Multivariable wavelet finite element-based vibration model for quantitative crack identification by using particle swarm optimization," Journal of Sound and Vibration, vol. 375, pp. 200 216, 2016.

[39] R. Thangaraj, M. Pant, A. Abraham, and P. Bouvry, "Particle swarm optimization: hybridization perspectives and experimental illustrations," Applied Mathematics \& Computation, vol. 217, no. 12, pp. 5208-5226, 2011.

[40] M. Marinaki, Y. Marinakis, and G. E. Stavroulakis, "Vibration control of beams with piezoelectric sensors and actuators using particle swarm optimization," Expert Systems with Applications, vol. 38, no. 6, pp. 6872-6883, 2011.

[41] M. Korürek and B. Dogan, "ECG beat classification using particle swarm optimization and radial basis function neural network," Expert Systems with Applications, vol. 37, no. 12, pp. 7563-7569, 2010.

[42] S.-W. Fei, "Diagnostic study on arrhythmia cordis based on particle swarm optimization-based support vector machine," Expert Systems with Applications, vol. 37, no. 10, pp. 6748-6752, 2010.

[43] International Organization of Standardization, "Cranesdesign principles for loads and load combinations-part 1: general requirements," ISO 8686-1, ISO, Geneva, Switzerland, 2012.

[44] International Organization of Standardization, "Cranestolerances for wheels and travel and traversing tracks-part 1: general requirements," ISO 12488-1, ISO, Geneva, Switzerland, 2012. 
[45] B. Zheng, X. Gao, and C. Zhang, "Radial integration BEM for vibration analysis of two- and three-dimensional elasticity structures," Applied Mathematics and Computation, vol. 277, pp. 111-126, 2016.

[46] T.-C. Chen, C. Su, Z.-Q. Hu, and H.-T. Ma, "An explicit time-domain method in sensitivity analysis of non-stationary random responses," Journal of Vibration Engineering, vol. 28, no. 4, pp. 503-509, 2015 (Chinese).

[47] Z. Hu, C. Su, T. Chen, and H. Ma, "An explicit time-domain approach for sensitivity analysis of non-stationary random vibration problems," Journal of Sound and Vibration, vol. 382, pp. 122-139, 2016.

[48] M. J. Griffin and E. M. Whitham, "Individual variability and its effect on subjective and biodynamic response to whole-body vibration," Journal of Sound and Vibration, vol. 58, no. 2, pp. 239-250, 1978. 


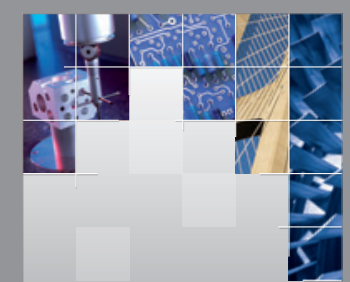

\section{Enfincering}
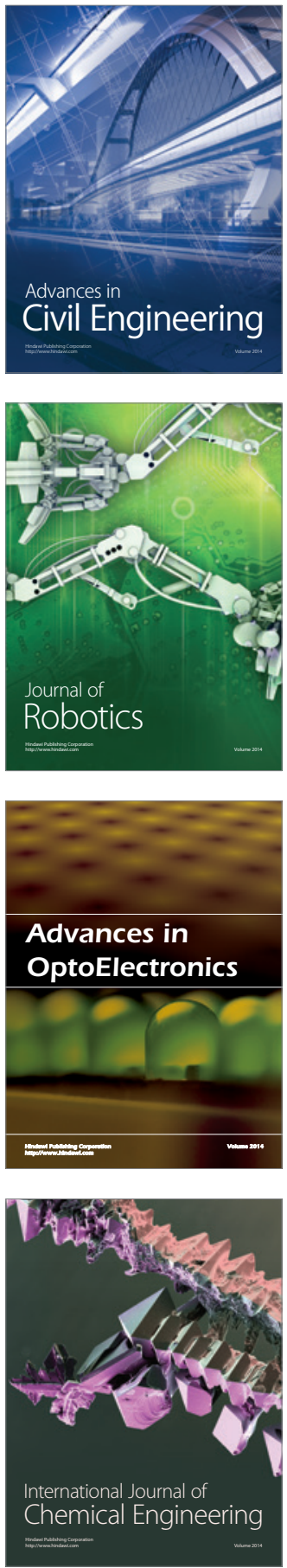

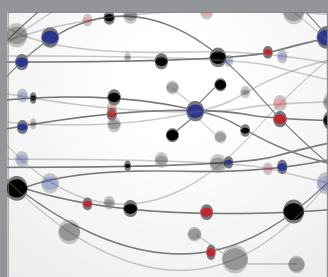

The Scientific World Journal

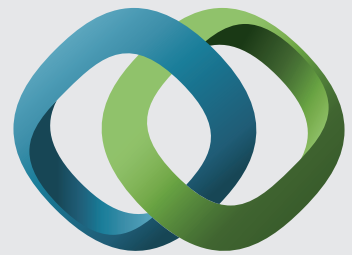

\section{Hindawi}

Submit your manuscripts at

https://www.hindawi.com
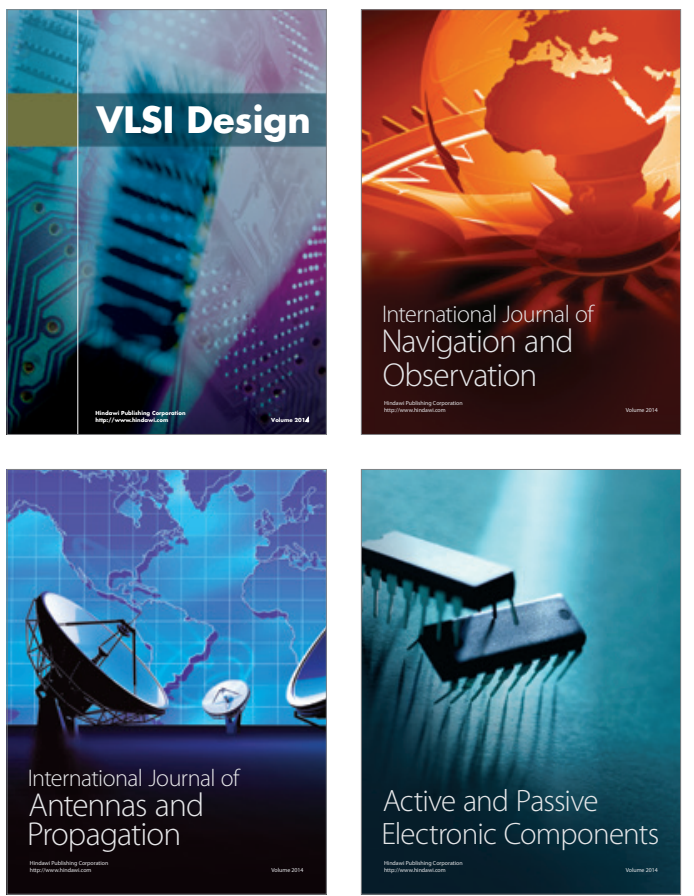
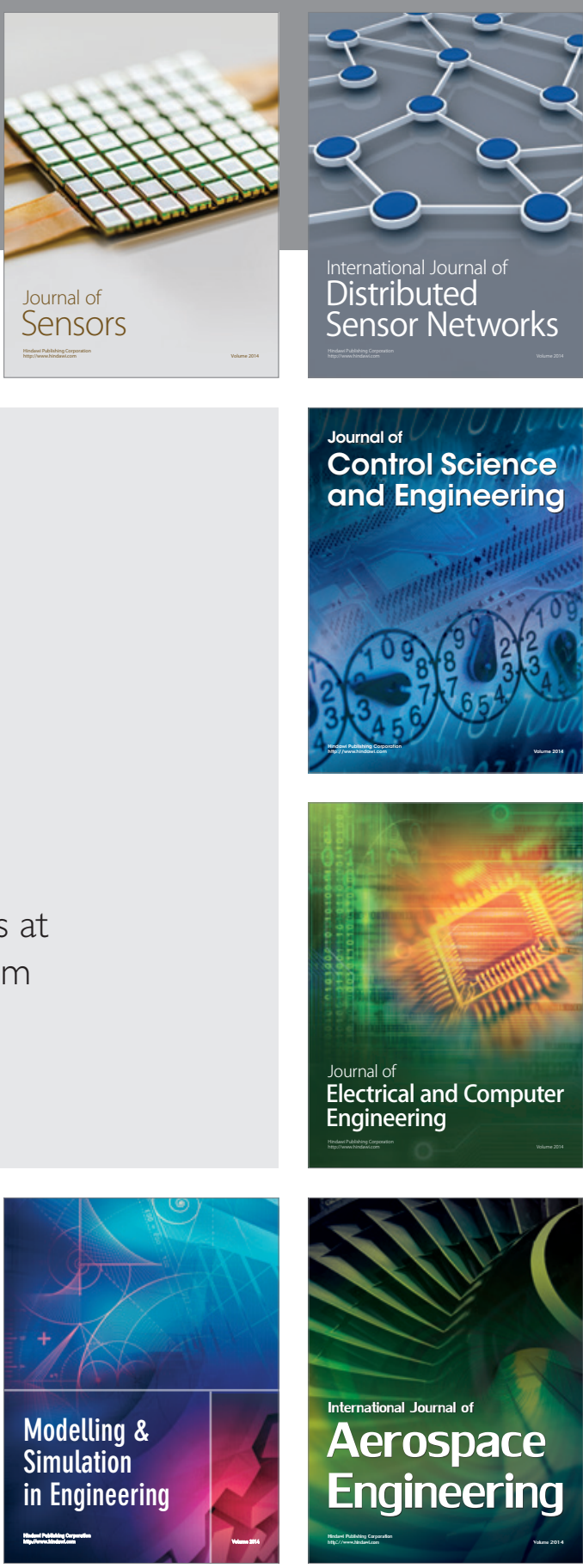

International Journal of

Distributed

Sensor Networks

$-$

Joumal of

Control Science

and Engineering
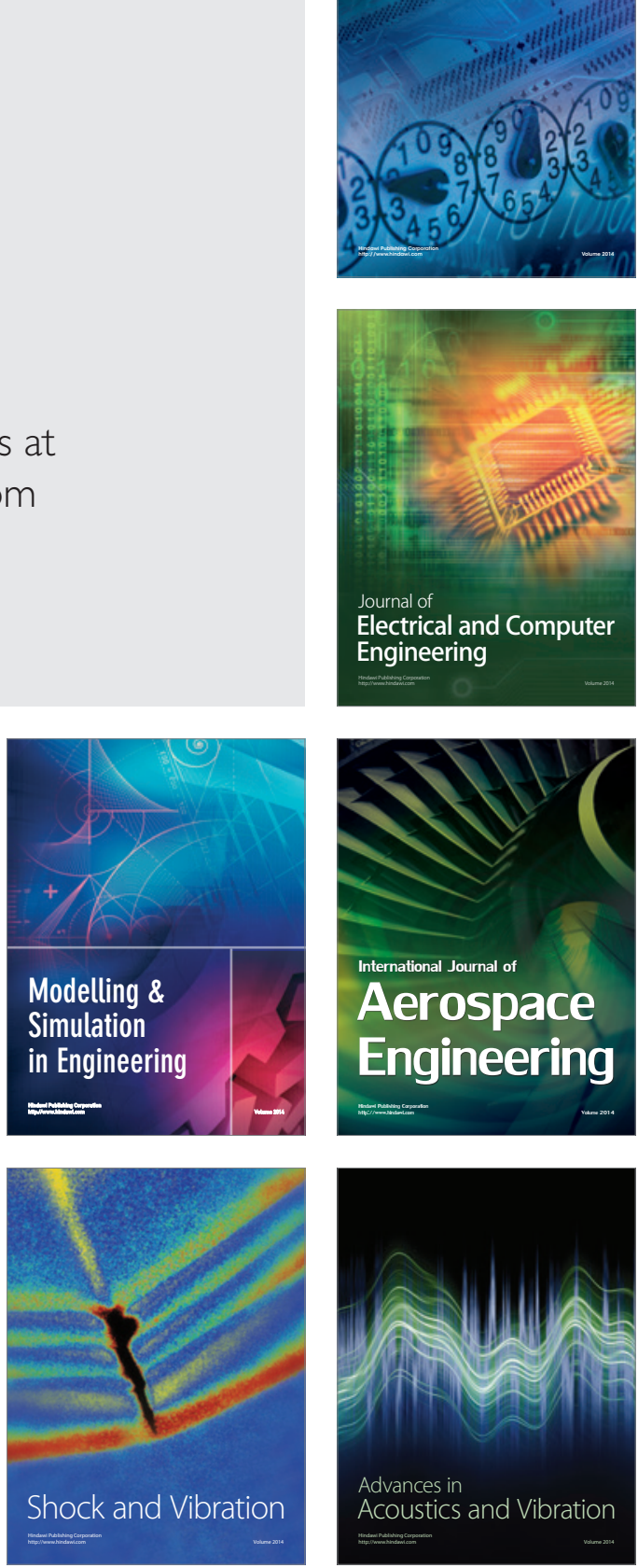